This PDF is a selection from a published volume from the National Bureau of Economic Research

Volume Title: Social Security Programs and Retirement around the World: Micro-Estimation

Volume Author/Editor: Jonathan Gruber and David A. Wise, editors

Volume Publisher: University of Chicago Press

Volume ISBN: 0-226-31018-3

Volume URL: http://www.nber.org/books/grub04-1

Publication Date: January 2004

Title: Micro-Modeling of Retirement Behavior in Italy

Author: Agar Brugiavini, Franco Peracchi

URL: http://www.nber.org/chapters/c10704 


\title{
Micro-Modeling of Retirement Behavior in Italy
}

\author{
Agar Brugiavini and Franco Peracchi
}

\subsection{Introduction}

This paper presents an empirical analysis of the retirement decisions of Italian workers. We emphasize the role played by dynamic incentives that are built in the social security system, which encourage (or discourage) retirement. The basic idea is that, at any given age and based on the available information, workers compare the expected present value of two alternatives, retiring today and working one more year, and then choose the one that is best. A key role in this kind of comparison is played by social security wealth for which the level and the changes on a year-to-year basis and over the worker's residual life reflect the institutional features of the social security system. The various incentive measures that we consider differ in the precise weight given to the social security wealth that workers accrue as they continue to work. These incentive measures are relevant in explaining retirement decisions as there are substantial gains or losses from retiring at particular ages, according to the prevailing legislation. Notice, however, that our model does not pretend to be a structural representation of the re-

Agar Brugiavini is associate professor of economics at the University of Venice, Ca'Foscari, Italy, and research associate at the Institute for Fiscal Studies, London, United Kingdom. Franco Peracchi is professor of econometrics at the University of Rome, Tor Vergata, Italy.

We thank Franco Mariuzzo and Ronni Pavan for excellent research assistance. We also thank the Bank of Italy, the Instituto Nazionale della Previdenza Sociale (INPS) administration and the Instituto Nazionale di Statistica (ISTAT) for providing us with data. Financial support from the European Union (EU)-sponsored Training and Mobility of Researchers Programme (TMR) network on Saving and Pensions, and the European Science Foundation and the Ministero dell'Università e della Ricera Scientifica e Tecnologica (MIUR) are gratefully acknowledged. The usual disclaimer applies. 
tirement process, as a worker's decision is modeled here following a simple reduced-form approach in which the incentive measures enter as predictors of a worker's binary choice in addition to standard variables, such as sex, age, and other background variables.

We use a longitudinal sample of Italian workers drawn from the social security archive containing the information on private-sector employees. We have twenty years of data available and can follow workers from the moment they start an employment spell in the private sector until they permanently leave the archive. Hence, we can model age-earnings profiles for all workers in the sample. This enables us to project their earnings forward and compute social security wealth in order to carry out the empirical analysis described above. Results from the estimated binary-choice model are then used to predict retirement probabilities under alternative policy arrangements. A basic feature of the simulated policies is to make retirement (particularly early retirement) more costly or to make eligibility requirements more stringent. Because changes in policy imply changes in the incentive measures, we expect to observe an impact on retirement probabilities.

Our results suggest that incentives are important in explaining retirement decisions, although the interaction of age and dynamic incentives is rather complex. In some of our policy simulations, we observe a shift in the age hazard into retirement toward older ages and also (although less frequently) an increase of the mean retirement age in response to the policy change.

The remainder of the paper is organized as follows. Section 6.2 reviews the recent situation of the Italian social security system in terms of expenditure trends and financial viability. It also describes recent institutional changes and labor market trends. Section 6.3 provides a description of the available data and discusses the methodology and the results of estimating age-earnings profiles. Section 6.4 looks at the definitions of the incentive variables and highlights some of the methodological issues involved in computing these measures in our sample. Finally, section 6.5 presents the results of the econometric exercise, as well as the results of the simulations.

\subsection{Recent Situation and Institutional Details}

In this section, we briefly describe the current situation of the Italian social security system. After summarizing the institutional details of the system before the beginning of the reform process in 1992, we look at the steady state characteristics of the system introduced with the 1995 reform. For the scope of this study, the transitional arrangements are also important. Finally, we discuss recent trends in retirement patterns and review the results of the available empirical literature. 


\subsubsection{Recent Expenditure Trends}

Figure 6.1 shows the historical trends in the number of pensions (top-left panel), average pension amounts (top-right panel), total pension expenditure (bottom-left panel) and the ratio of pension expenditure to gross domestic product (GDP; bottom-right panel) as measured by the National Institute of Statistics (ISTAT 1999). We only consider expenditure on oldage, disability, and survivor pensions, thus excluding noncontributive pensions. In the twenty-five years from 1975 to 1999, the number of pensions outstanding grew by more than 40 percent, from 12.4 to 17.8 million, and the average pension amount more than doubled in real terms, from L7.1 to L16.1 million at 1998 prices. Therefore, total expenditures increased by more than three times and the ratio of pension expenditure to GDP rose by more than 5 percentage points, from 8.4 to 13.6 percent. No other country in the EU experienced such a dramatic growth.

The increase in the number of pensions outstanding reflects both the progressive aging of the Italian population and the steady reduction of the average retirement age, largely due to people taking advantage of the possibility of retiring with a seniority pension (pensione di anzianita') after
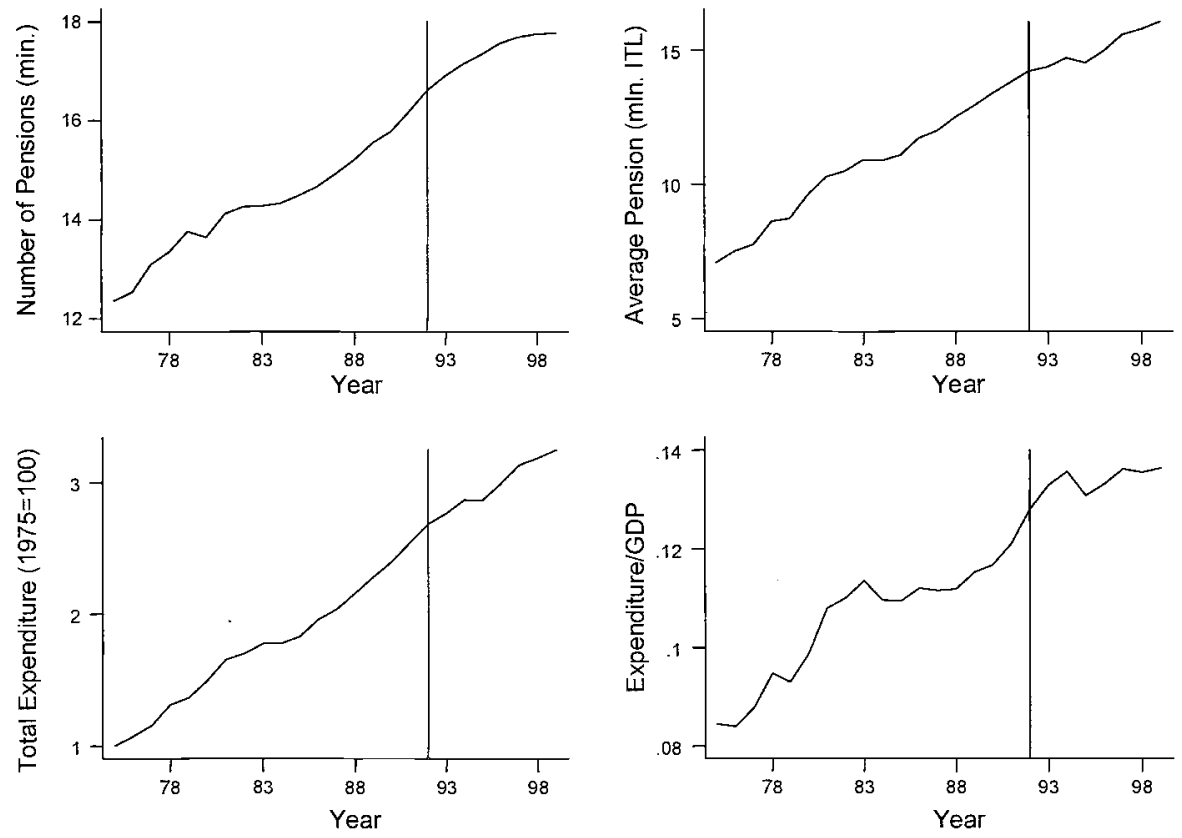

Fig. 6.1 Number of pensions, pension expenditure, average pension, and expenditure-GDP ratio, 1975-98: Old-age, disability, and survivor pensions Source: ISTAT (various years). 
thirty-five years of contributions to the system (or even less for publicsector employees) without any actuarial reduction. On the other hand, the rise of average pensions is due to the sharp increase of lifetime earnings of successive cohorts of workers, a number of legislated changes that made the system progressively more generous, and the fact that, until 1992, outstanding pensions were linked to productivity growth.

Notice that, after increasing very quickly during the 1970s, pension expenditure slowed down during the first half of the 1980s. Expenditure resumed growing very rapidly from the mid-1980s to the early 1990s when two major reforms, in 1992 and 1995 (known respectively as the "Amato reform" and the "Dini reform" from the names of the prime ministers then in charge), apparently succeeded in stabilizing the ratio of pension expenditure to GDP. The next subsections discuss in more detail the rules prevailing before 1993 and the reforms of the 1990s.

\subsubsection{The Rules Prevailing Before 1993}

The Italian social security system is based on a variety of institutions administering public pension programs. About two-thirds of the workforce is insured with the National Institute of Social Security (Istituto Nazionale della Previdenza Sociale, or INPS). ${ }^{1}$ This is responsible for a number of separate funds, of which the most important covers the private-sector employees (Fondo Pensioni Lavoratori Dipendenti, or FPLD).

In this section, we describe the main rules prevailing before 1993. In 1992, a major reform was introduced, followed by another major reform in 1995, and further changes in 1997. These reforms are discussed in section 6.2.3. We focus on the FPLD fund because our empirical exercise uses data on private-sector employees. This description is incomplete, however, as important differences exist between the rules for private- and public-sector employees. Furthermore, the self-employed are characterized by a separate fund and enjoy a particularly favorable treatment in terms of both contributions and benefit calculation.

\section{Payroll Social Security Taxes}

The resources to the system come mainly from the employers' and employees' contributions. Outlays exceed revenue, however, and the resulting deficit is financed by the central government, which has come under increasing pressure to pay for pensions.

The payroll tax is unevenly shared between the employer and the employee. For the FPLD, the total payroll tax was 24.51 percent of gross earnings until 1992, of which 7.15 percent was levied on the employee. This grew to 27.17 percent in 1992 (of which the worker paid 8.34 percent and

1. It covers the vast majority of the private-sector employees and the self-employed. Publicsector employees are covered by a completely separate administration Instituto Nazionale della Prividenza per i Dependenti delle Amministrazioni Pubbliche (INPDAP). 
33 percent in 1998 (of which the worker pays 8.89 percent). Social security taxes for public-sector employees have been lower in the past but are now in line with those in the private sector. ${ }^{2}$

Employees contribute a further 7.41 percent to a severance-pay fund known as Trattamento di Fine Rapporto (TFR). These contributions are retained by the employer and build up in a fund that offers a legislated rate of return ( 1.5 percent plus 75 percent of the annual inflation rate) and provides a lump-sum benefit when the employee leaves the firm.

\section{Eligibility}

Before 1993, eligibility requirements were met when a male worker reached age sixty (for a female worker, age fifty-five) after contributing for at least fifteen years. However, the existence of an early retirement option made the age requirement largely irrelevant for private-sector workers with uninterrupted work careers because they could claim early retirement benefits at any age after completing thirty-five years of contributions. ${ }^{3}$

A feature that is important when discussing labor supply incentives provided by the system is the retirement earnings test. Italian workers can draw a pension and earn income at the same time, but there are earnings cutoffs that tend to discourage this choice. The cutoffs changed over time and have been affected by the reforms. Prior to 1993, private-sector employees could receive an old-age pension along with earnings only if earnings did not exceed the minimum pension benefit. Early retirement benefits could not be received along with earnings. ${ }^{4}$

Eligibility criteria and the rules for benefit calculations were responsible for the highly redistributive nature of the pension program. Most importantly, they affected retirement decisions and the choice between dependent employment and self-employment in a nontrivial fashion. In particular, there was a clear incentive to early retirement since no actuarial penalty applied to early retirees. For example, a private-sector employee who started working at age sixteen could retire at age fifty-one with a full pension. This helps to explain why exit from the labor force increased significantly over time for the age group fifty to fifty-nine.

\section{Benefit Computation}

Pensionable earnings for private sector employees (covered by the FPLD) were computed by averaging the earnings of the last five years

2. While 33 percent is the level of the payroll tax used in the benefit-calculation formula, the actual amount paid is 32.7 percent. In contrast to employees, social security taxes for the selfemployed remain considerably lower; the tax rate is notionally set at 20 percent, but the effective payroll tax rate is 15 percent.

3. For a male public-sector employee, only twenty years of contributions were required (fifteen years for a married woman).

4. Note that the self-employed could claim early retirement without restrictions on earnings. Also, cutoff points on earnings did not apply to this group of workers when claiming oldage benefits. Early retirement benefits are reduced for the working self-employed only in 1998. 
before retirement. ${ }^{5}$ Earnings were taken before tax and converted into real amounts using a consumer price index. Pension benefits were then obtained as the product of three terms: pensionable earnings, the number of years of contribution (up to a maximum of forty), and a 2 percent factor per year of contribution (referred to as the "rate of return"). Hence, a worker could get 80 percent of his pensionable earnings at most. If retirement was postponed, additional years of work beyond age forty did not count for benefit computation, although they were included in pensionable earnings as they replaced earnings of earlier years. As discussed later in section 6.4, this has important implications for the age profiles of social security wealth.

The system was highly progressive (and it still is) because of both earnings caps (i.e., earnings entering the benefit computation were capped) and a minimum benefit level. Between 1969 and 1988, only earnings up to a legislated limit would contribute to pensionable earnings, while after 1988 different rates of return would be applied to different pensionable-earnings brackets. ${ }^{6}$

Contributions were not subject to income taxes, but social security benefits were taxed at the normal income tax rates. ${ }^{7}$ For all funds, benefits were indexed both to consumer price inflation and real earnings growth. ${ }^{8}$ The former was measured by the consumer price index but was implemented in a slightly staggered fashion (e.g., if the pension amount is more than three times the minimum benefit, then indexing is based only on 75 percent of the price change). The measure of earnings growth took into account changes in real wages in both the private- and the public-sector.

\section{Minimum Benefit}

This provision of the Italian system is important for at least two reasons. First, the number of retirees involved is nonnegligible (see table 6.4). Second, the minimum benefit is often used as a benchmark for income transfers from other assistance programs. In practice, if the benefit formula results in a benefit level below a legislated threshold, then the benefit itself is

5. It is worth recalling that public-sector employees had their benefit level based on final salary rather than average earnings of the last five years of work.

6. For example, in 1985 pensionable earnings in excess of $€ 16,527$ (1.6 times the average earnings of that year) would not be included in benefit calculations. After 1988, the constraint became less stringent, but a lower rate of return was applied to pensionable earnings in excess of the legislated limit. In 1995, a 2 percent rate applied to the first €29,438 (again, 1.6 times the average earnings), a 1.5 percent rate to pensionable earnings between $€ 29,438$ and $€ 39,250$ ( 2.2 times the average earnings), and a 1.25 percent rate to pensionable earnings between $€ 39,250$ and $€ 49,063$ (2.7 times the average earnings). Finally, a 1 percent rate of return applied to the top earnings bracket. The generosity of the system toward low-income workers was further increased by the minimum benefit provision, that is, a floor on the benefit level.

7. The principle of taxing pension benefits, but not taxing contributions, remains valid after the reforms.

8. These growth rates were combined in a specific index computed by the INPS administration (coefficiente di perequazione). The frequencies were every four months between 1983 and 1986, every six months between 1986 and 1992, and annually after the 1992 reform. 
increased up to the threshold. Until 1983, this provision could be applied to more than one pension for the same retiree. Now, it only applies to one pension, leaving the other benefits at their original level. Minimum benefits are means tested. Until 1992, the test was based only on the claimant's income, excluding the income of the spouse. For example, in 1985, the means test had a cutoff at twice the minimum level (roughly $€ 4,130$ of that year, corresponding to 17 percent of mean household income of the same year). A limit on individual income still applies to singles. For married couples, what matters now is instead the sum income of both spouses, which must be less than four times the minimum level (approximately $€ 4,130$ in 1995, corresponding to 18 percent of mean household income).

\subsubsection{The Reforms of the 1990s}

Some of the issues emerging from the preceding description of the pre1993 system have been tackled by the recent reforms. A first reform (the Amato reform) was passed by Parliament in 1992 and took effect in 1993. It raised the normal retirement age and the minimum number of years of contribution by five years, lengthened the reference period for calculating pensionable earning, restricted the special eligibility conditions applying to public-sector employees, eliminated pension indexation to real wage growth by indexing pensions only to price inflation, and increased social security contributions.

The 1992 reform was the first signal of a coherent attempt at redesigning the social security system and reducing pension expenditures. However, it left the rules governing early retirement almost untouched and, overall, it did not produce the much-needed short-term savings in the social security budget. ${ }^{9}$ This partly justified the need of a second reform in 1995 (the Dini reform), which totally changed the basic rules for granting benefits to future retirees and tried to harmonize the actuarial rates of return for early and late retirees.

The 1995 reform goes under the heading of "virtual" funding since public pensions are still financed through a PAYG scheme, but each worker holds a claim based on a fund that remains only virtual. The new system is therefore a notionally defined-contribution system that is similar to the one recently adopted by Sweden. Crucial elements of the reform are: (a) how the accrued value of the virtual fund is computed, (b) how it is then converted into an annuity at the time of retirement, and (c) the indexation rule adopted for the pensions outstanding. Lifetime tax payments are capitalized at an annual rate equal to a (five-year) moving average of past GDP-growth rates. The level of benefits (the annuity) no longer depends on final earnings, as in the previous system, but is instead proportional to the value of accrued social security tax payments. The proportionality factor increases more than

9. Section 6.2.4 analyzes some of the effects of the 1992 reform and of the 1995 reform. 
proportionally with the retirement age up to age sixty-five and then flattens out. Its current age profile implies an actuarial reduction of 23 percent in pension benefits for retirement at age fifty-seven, relative to retirement at age sixty-five, and has been legislated taking into account two key elements: the average residual life expectancy at retirement based on the 1990 life tables and a fixed real rate of return of 1.5 percent that reflects long-run forecasts of annual GDP growth. Finally, outstanding pensions are going to be indexed to price inflation only and not to real wage growth.

The 1995 reform changed eligibility rules by allowing people to retire at any age after reaching age fifty-seven provided that they meet two conditions: (a) they must have contributed to the system for at least five years, and (b) the value of their pension must be at least 1.2 times the noncontributive pension that is paid to those aged sixty-five and older who have no other income source ("social" pension). Besides changing the benefit formula and the eligibility rules, the 1995 reform also took a number of steps in the direction of unifying the rules of the many schemes in which the Italian social security system is organized.

Once phased in, the 1995 reform will imply a more transparent and actuarially fair pension system. The reason is twofold. First, benefits are more clearly linked to contributions than it was the case with the previous final-salary type formulae, thus reducing negative incentive effects on labor supply. Second, the whole workforce is now covered by essentially the same system, thus reducing incentive effects in favor of certain types of employment (public-sector employees and the self-employed). The system is not completely neutral, however, and a number of provisions still exist that tend to favor the self-employed. ${ }^{10}$

Table 6.1 summarizes the key features of the three regimes: the one prevailing before the 1992 reform (denoted as pre-1993 regime), the one prevailing at the steady state after the 1992 reform, and the ones after the 1995 reform. In practice, both the 1992 and the 1995 reforms are characterized by a very long transitional period. For workers with less than fifteen years of contributions at the end of 1992, the provisions for the transitional period establish eligibility and benefit-computation criteria on a pro-rata basis. This method allows the rules of the old regime to hold for the fraction of years in employment under that regime, while the remaining fraction is regulated by the new rules. For these workers, eligibility and social security benefits are therefore computed taking into account three different systems of legislation. For workers with at least fifteen years of contribution at the end of 1992, the rules of the pre-1992 regime apply with only small changes.

10. For example, the self-employed still enjoy lower contribution rates (see also note 2). Furthermore, not all funds are affected by the reform; for example, a number of special funds for professional self-employed (such as lawyers, architects and building engineers, and accountants) still work according to their own rules, although attempts to harmonize these rules with those of the employees fund are taking place. 
Table 6.1

Key Features of the Pre-1993 Regime and the 1992 and 1995 Reforms (at the steady-state)

\begin{tabular}{|c|c|c|c|}
\hline & Pre-1993 Regime & 1992 Reform & 1995 Reform \\
\hline Normal retirement age & $\begin{array}{l}60 \text { (men) } \\
55 \text { (women) }\end{array}$ & $\begin{array}{l}65 \text { (men) } \\
60 \text { (women) }\end{array}$ & $\begin{array}{l}\text { Any age after } 56 \\
\text { (both men and } \\
\text { women) }\end{array}$ \\
\hline Transitional period & & Until about 2032 & Until about 2035 \\
\hline Pensionable earnings & $\begin{array}{l}\text { Average of last } 5 \text { years } \\
\text { real earnings (con- } \\
\text { verted to real values } \\
\text { through price index) }\end{array}$ & $\begin{array}{l}\text { Career average earn- } \\
\text { ings (converted to real } \\
\text { values through price } \\
\text { index }+1 \% \text { ) }\end{array}$ & $\begin{array}{l}\text { Career contributions } \\
\text { (capitalized using a } \\
5 \text {-year moving aver- } \\
\text { age of GDP growth } \\
\text { rate) }\end{array}$ \\
\hline Pension benefit & $\begin{array}{l}2 \% \cdot(\text { pensionable } \\
\text { earnings }) \cdot(t), \text { where } t \\
\text { is years of tax pay- } \\
\text { ments }(\leq 40)\end{array}$ & $\begin{array}{l}2 \% \cdot(\text { pensionable } \\
\text { earnings }) \cdot(t) \text {, where } t \\
\text { is years of tax pay- } \\
\text { ments }(\leq 40)\end{array}$ & $\begin{array}{l}\text { Proportional to capi- } \\
\text { talized value of career } \\
\text { contributions, the } \\
\text { proportionality factor } \\
\text { increasing with age at } \\
\text { retirement (from } \\
.04720 \text { at age } 57 \text { to } \\
.06136 \text { at age } 65 \text { ) }\end{array}$ \\
\hline Pension indexation & $\begin{array}{l}\text { Cost of living plus real } \\
\text { earnings growth }\end{array}$ & Cost of living & Cost of living \\
\hline Pension to survivor & $\begin{array}{l}60 \% \text { to spouse, } 20 \% \text { to } \\
\text { each child; } 40 \% \text { to each } \\
\text { child (if no spouse) }\end{array}$ & Same & Same \\
\hline $\begin{array}{l}\text { Years of contributions } \\
\text { for eligibility }\end{array}$ & 15 & 20 & 5 \\
\hline $\begin{array}{l}\text { Early retirement } \\
\text { provision }\end{array}$ & $\begin{array}{l}\text { Any age if contributed } \\
\text { to SS for } 35 \text { years or } \\
\text { more, no actuarial } \\
\text { adjustment }\end{array}$ & $\begin{array}{l}\text { Any age if contributed } \\
\text { to SS for } 35 \text { years or } \\
\text { more, no actuarial } \\
\text { adjustment }\end{array}$ & $\begin{array}{l}\text { No early retirement } \\
\text { provision }\end{array}$ \\
\hline Total payroll tax & $\begin{array}{l}24.5 \% \text { of gross } \\
\text { earnings }\end{array}$ & $\begin{array}{l}27.17 \% \text { of gross } \\
\text { earnings }\end{array}$ & $\begin{array}{l}32.7 \% \text { of gross } \\
\text { earnings }\end{array}$ \\
\hline
\end{tabular}

Therefore, people will retire under the pre-1993 system until about the year 2015. During the following fifteen to twenty years, an increasing fraction of a retiree's pension will be computed on the basis of the new system. It will only be around 2030 that a significant number of workers will start retiring fully under the 1995 rules.

In our paper, the only relevant transitional phase is the one introduced by the 1992 reform. According to these rules, the normal retirement age for a private-sector employee gradually increases to reach sixty-five for men and sixty for women in year 2000. It should be mentioned that between 1992 and 1997 there have been spells (typically lasting between six months and one year) in which many employees were not allowed to take early 
Table 6.2

Rules for Benefit Computation Prevailing During the Transitional Period After the 1992 Reform

Case

Pensionable Earnings Computation

A1: Private sector-Senior ${ }^{\text {a }}$ (years before 1993)

A2: Private sector-Senior (years after 1993)

B1: Private sector-Junior (years before 1993)

B2: Private sector-Junior (years after 1993)

C1: Public sector-Senior (years before 1993)

C2: Public sector-Senior (years after 1993)

D1: Public sector-Junior (years before 1993)

D2: Public sector-Junior (years after 1993)
Average of last 5 years' real earnings

Average of last 6.5 years' earnings, to gradually become last 10 years' earnings after 2002

Same as A1

Average of last 8 years' earnings, to gradually become last 15 years' earnings after 2002 and further increasing thereafter.

Last month's real earnings

Average of last 1.5 years' earnings, to gradually become last 10 years' earnings after 2012

Same as C1

Average of last 3 years' earnings, to gradually become last 10 years' earnings after 2012 and further increasing thereafter

Notes: Table 6.2 focuses on employees, but similar rules apply to the self-employed. Consider, for example, a case A worker with at least 15 years of seniority at the end of 1992. His pension depends on a weighted average of pensionable earnings computed under case A1 and pensionable earnings computed under case A2, with weights determined by the number of years in the system before and after 1993 respectively.

aSeniors = At least 15 years in the system at the end of 1992. "Years before 1993" are the years of valid tax payments to the social security administration completed before 1993.

retirement. ${ }^{11}$ During the transitional phase, the benefit calculation distinguishes workers depending on their seniority and deals differently with contributions paid before and after the reform as detailed in table 6.2. It is clear that the transitional rules mainly affect younger workers.

\subsubsection{Future Prospects}

So far, the effects of the 1995 reform on pension expenditure have been only minor. After 1995, pension expenditure resumed growing at rates that, although lower than in the past, have nevertheless been higher than GDP growth rates (figure 6.1). Furthermore, the slowdown of expenditure growth is largely the result of decisions taken in 1992, namely the switch from the double indexing (to price inflation and productivity growth) of pensions to price-inflation indexing; the introduction of limitations to early retirement; and the gradual increase of the normal retirement age. However, as we discuss below, the changes in eligibility for old-age and early retirement benefits brought about by the reforms have not been particularly effective: the elimination of the double indexation has been by far the most important change.

11. The 1995 reform has gradually removed these constraints. In the transitional phase starting in 1996, public-sector employees who claimed early retirement benefits suffered minor reductions on the basis of actuarial adjustment factors. 
○ age 50-54 - age 55-59

+ age $60-64$
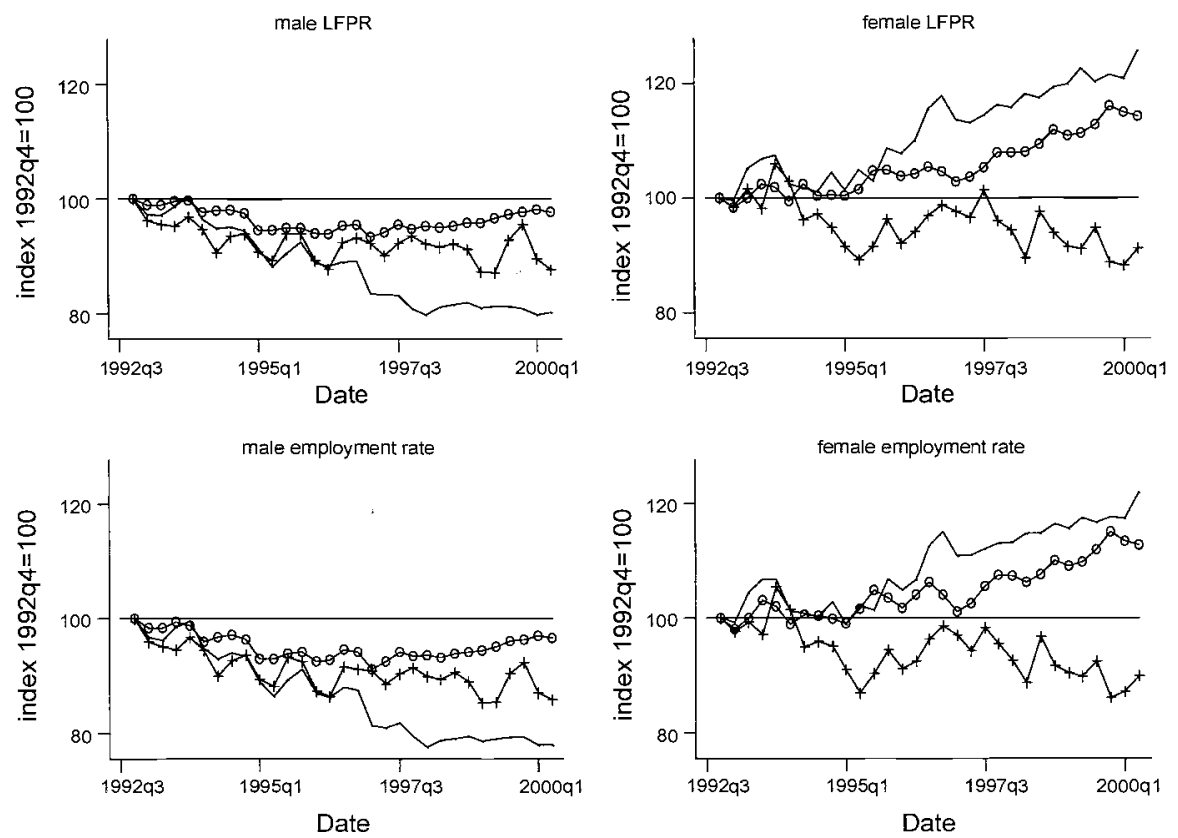

Fig. 6.2 Recent trends in labor force participation rates and employment rates, October 1992-April 2000 (index October 1992 = 1,000)

Source: Authors' calculations based on the micro-files of the Labor Force Survey 1992-2000.

In order to evaluate the future prospects of the Italian public pension system, we need to start from the available demographic projections. Indeed, the ones produced by ISTAT for the period 1996-2050 have attracted considerable attention in the public policy debate. They portray a rather worrisome picture as the elderly dependency ratio - that is, the ratio between the elderly population (people aged sixty and older) and the working age population (people aged twenty to fifty-nine) - is expected to grow from 40 percent in 1996 to 83 percent in 2050. These projections have been criticized for being too optimistic because they rule out further declines in mortality. On the other hand, they appear to underestimate migration, which could play an offsetting role.

Besides demographics, the other crucial variable for judging the future viability of the social security system is labor market trends. Past trends in labor force participation, described in Brugiavini (1999), show a progressive detachment of older workers from the labor force. Here we look at more recent evidence on the labor market behavior of older workers.

Figure 6.2 shows the time series of labor force participation rates (top panels) and employment rates (bottom panels) by age group for the period 
Table 6.3 Current Retirement Eligibility Rules

\begin{tabular}{|c|c|c|c|c|c|c|}
\hline \multirow[b]{2}{*}{ Year } & \multicolumn{2}{|c|}{ INPS (Private Sector) } & \multicolumn{2}{|c|}{ INPDAP (Public Sector) } & \multicolumn{2}{|c|}{ Self-Employed } \\
\hline & $\begin{array}{c}\text { Age and } \\
\text { Years of } \\
\text { Contribution }\end{array}$ & $\begin{array}{c}\text { Only } \\
\text { Years of } \\
\text { Contributions }\end{array}$ & $\begin{array}{c}\text { Age and } \\
\text { Years of } \\
\text { Contribution }\end{array}$ & $\begin{array}{c}\text { Only } \\
\text { Years of } \\
\text { Contribution }\end{array}$ & $\begin{array}{c}\text { Age and } \\
\text { Years of } \\
\text { Contribution }\end{array}$ & $\begin{array}{c}\text { Only } \\
\text { Years of } \\
\text { Contribution }\end{array}$ \\
\hline 1998 & 54 and 35 & 36 & 53 and 35 & 36 & 57 and 35 & 40 \\
\hline 1999 & 55 and 35 & 37 & 53 and 35 & 37 & 57 and 35 & 40 \\
\hline 2000 & 55 and 35 & 37 & 54 and 35 & 37 & 57 and 35 & 40 \\
\hline 2001 & 56 and 35 & 37 & 55 and 35 & 37 & 58 and 35 & 40 \\
\hline 2002 & 57 and 35 & 37 & 55 and 35 & 37 & 58 and 35 & 40 \\
\hline 2003 & 57 and 35 & 37 & 55 and 35 & 37 & 58 and 35 & 40 \\
\hline 2004 & 57 and 35 & 38 & 57 and 35 & 38 & 58 and 35 & 40 \\
\hline 2005 & 57 and 35 & 38 & 57 and 35 & 38 & 58 and 35 & 40 \\
\hline 2006 & 57 and 35 & 39 & 57 and 35 & 39 & 58 and 35 & 40 \\
\hline 2007 & 57 and 35 & 39 & 57 and 35 & 39 & 58 and 35 & 40 \\
\hline 2008 & 57 and 35 & 40 & 57 and 35 & 40 & 58 and 35 & 40 \\
\hline
\end{tabular}

Source: INPS, Information on Early Retirement (available at http:www.inps.it) and Ministero del Lavoro, Social Security (available at http://www.miniwelfare.it).

Note: Rules prevailing after 1998 according to the Law 449/1997. These rules apply to white-collar employees, they differ only slightly for blue-collar employees.

from October 1992 to April 2000 and separately for men and women. The data have been computed from the micro-files of the quarterly labor force survey and have been normalized by taking indexes with an October 1992 base equal to 100 . For men, a relatively stable labor force participation rate (and employment rate) is observed after 1998 in all age groups. This occurs after a period of marked decline in participation. It is interesting to note that, after 1996, labor force participation is slowly starting to increase for the age group fifty to fifty-four, while it remains at a low level for the other two age groups. Women aged fifty to fifty-four and fifty-five to fifty-nine also show increasing participation after the beginning of 1995, whereas men and women aged sixty to sixty-four show a very similar negative trend.

The interpretation of these findings is that the recent reforms have affected retirement behavior in two ways. Initially, reforms had mainly an announcement effect and workers-particularly younger retireesclaimed retirement as soon as they could in order to avoid losing the option of leaving the labor market in subsequent years. After 1997, however, the eligibility rules built into the new system start to become binding (see table 6.3), and workers, particularly the younger cohorts of potential retirees, were forced to delay retirement. ${ }^{12}$ Overall, there is some evidence that the recent reforms of the Italian social security system have begun to

12. See also Franco (2000) for similar arguments in an appraisal of the recent Italian reforms. 
have an impact on the retirement behavior of older workers, although this is unlikely to revert the pension expenditure trends of the recent past or to counteract the effects of the aging process of the Italian population.

\subsubsection{Literature Review}

To our knowledge, only three studies are currently available in Italy that try to explain the individual decisions to retire from the labor force, particularly the choices of retirement age and the specific pathway of exit. The problem, however, is of great importance. Take, for example, the dramatic decline in labor force participation of men aged fifty to fifty-nine following the start of the lengthy process of social security reforms in 1992. This decline has been missed entirely by the reduced-form model used by the actuaries of the main social security funds, which are based on simple extrapolation of the trends prevailing up to the early 1990s (see, e.g., INPS 1995).

The first study, by Miniaci (1998), analyses the effects of socioeconomic and demographic characteristics on the choice of labor force status using the 1995 Survey of Household Income and Wealth (SHIW) carried out by the Bank of Italy. The sample consists of heads of households and their partners who were in the labor force at the age of forty-five (if women) or fifty (if men). The retirement age is obtained from the retrospective questions asked in the survey about the time when pension benefits were first received. The basic model is a multinomial logit specification with three states: working, receiving an old-age or seniority pension, and receiving other pensions (invalidity, survivor, or social pensions). The paper also estimates a Cox proportional-hazard model for the duration of stay in employment and separate pathways of exit (old-age or seniority pension, invalidity, or other), with and without the inclusion of the predicted value of the replacement rate among the covariates. The main findings show the presence of strong cohort effects towards earlier retirement, later retirement ages among the better-educated workers, lower replacement rates and later retirement ages among the self-employed, no evidence that public employees retire earlier, no evidence of a differential role of invalidity and other pensions between the north and the south, and little evidence of a replacement-rate effect on the expected retirement age.

The second and third study, by Spataro (2000) and Colombino (2000), respectively, take a more structural approach. The paper by Spataro estimates an option value model using a subset of the panel component of the SHIW for the years 1991 and 1993 (namely, men aged forty-five to sixtyfive who are full-time employees at the end of 1990). The estimation method is a pseudo-maximum likelihood based on the normality assumption. He compares the empirical results with reduced-form probit specifications and the original results in Stock and Wise (1990). In particular he shows that, relative to U.S. workers, Italian workers value their leisure 
more highly, are more risk averse, and have a lower intertemporal discount rate. He also shows that the option value model is unable to capture the peak in the retirement hazard at age sixty.

Finally, Colombino (2000) extends the probit model estimated by Zweimüller, Winter-Ebmer, and Falkinger (1996) for Austria to provide a structural interpretation in terms of utility comparisons between two mutually exclusive states (employed and retired). This interpretation is based on specific assumptions about the time profiles of the instantaneous utility of being employed and retired. The model is estimated using the 1993 SHIW for those aged forty and older. The empirical implementation of the model relies crucially on the imputation of potential earnings for those who are currently retired and on potential pension benefits for those who are currently employed. One of the main findings is that women are more sensitive than men to the rules and incentives of the system. The paper also contains an extension to the joint decision of a couple. This extension leads to a bivariate probit model whose parameters are subject to constraints and admit a structural interpretation. The model is used to simulate the effects of various policies (cut of pension benefits, elimination of seniority pensions, and complete phasing in of the 1992 and 1995 reforms), distinguishing between the effects due to the changes in the way pension benefits are computed, the changes in the criteria for pension eligibility, and the behavioral response to both changes. The main finding here is that behavioral effects are small, but not negligible.

\subsection{Data Description and Earnings Model}

\subsubsection{The Data}

Unlike the papers reviewed in section 6.2.5, all based on the Bank of Italy's SHIW, we use a random sample of administrative records from one of the INPS archives. ${ }^{13}$ The sample is drawn from the so-called INPS Workers Archive (Archive O1M), which contains records on all privatesector employees insured with INPS. The information on each employee is filled in by the employer on a standard form containing a small number of entries. We have a random sample of these employees in the form of a panel

13. This is a subsample (one out of one hundred) workers born either on 1 March or on 1 October of any possible year contained in the archive. We carried out a parallel analysis of retirement decisions using the Bank of Italy's SHIW data. The SHIW is a cross-sectional sample and contains a full set of demographic variables, relative to the household and its members, plus labor market variables. However, the panel component of SHIW is characterized by a very small sample size and very short time span: very few transitions into retirement are actually observed. Also questions in the SHIW survey are retrospective, and the survey is carried out, for the relevant period, every two years. Therefore, we decided to restrict the attention to the INPS sample. 
covering a period of about twenty years from 1973 to 1994 . The sample contains 10,000 workers entering the archive at any time during the period considered. Employment spells can last any number of years, and individuals can leave the sample and enter again in any subsequent year. The panel is therefore highly unbalanced.

The main advantages of using these data are that they span a fairly long time period and contain information on gross earnings (as opposed to net earnings, as in the SHIW), which form the basis for the calculation of social security benefits. However, there are several shortcomings.

1. The data set only covers private-sector employees, leaving out publicsector employees and the self-employed. Even for private-sector employees, however, coverage is not full, and a small fraction of them is not included.

2. The reason for a worker leaving the archive is not known: In addition to retiring, workers could die, become self-employed or public-sector employees, or simply stop working.

3. Important covariates (e.g., education level, spousal information, and other family background variables) are missing, and hence, we have very few demographic controls available: we do not know about marital status and cannot say much about differential mortality.

4. There is no information on receipt of disability or other types of benefits.

The initial sample selection, carried out in order to estimate suitable earnings histories, is as follows. We focus on workers between eighteen and seventy years of age. We drop observations for which one important indicator (such as age) is missing and individuals who work less than twentysix days a year. We also exclude from the analysis workers belonging to special INPS funds (nursery school teachers, local authorities, employees, and so forth). ${ }^{14}$ In order to estimate earnings profiles and eventually measure social security wealth, we further limit the sample by including only workers who are present in the sample for an uninterrupted period of at least five years (workers often appear for one year and then disappear from the sample for a long spell). The five-year minimum requirement is motivated by the fact that it corresponds to the minimum contributive period under the 1995 reform. We only keep workers who do not have substantial gaps (more than ten years missing) in their records. This is because we cannot say whether in that time span they were engaged in other labor market or nonlabor market activities (such as maternity leaves or undertaking fur-

14. We could include these observations to add variability across funds, but these workers represent only a small number (less than 100 observations) and tend to exhibit many gaps in their careers. 
Table 6.4

Fraction of Minimum Benefit Awards Over Total Awards, by Sex and Type of Benefits (end of 1999)

\begin{tabular}{|c|c|c|c|c|c|c|}
\hline \multirow[b]{2}{*}{ Age } & \multicolumn{2}{|c|}{$\begin{array}{l}\text { Old-Age and } \\
\text { Early Retirement }\end{array}$} & \multicolumn{2}{|c|}{ Disability } & \multicolumn{2}{|c|}{ Survivors } \\
\hline & Male & Female & Male & Female & Male & Female \\
\hline$\leq 50$ & 0.000 & 0.000 & 0.153 & 0.250 & 0.390 & 0.325 \\
\hline 51 & 0.000 & 0.000 & 0.169 & 0.310 & 0.326 & 0.308 \\
\hline 52 & 0.004 & 0.008 & 0.175 & 0.308 & 0.326 & 0.306 \\
\hline 53 & 0.007 & 0.020 & 0.174 & 0.325 & 0.298 & 0.297 \\
\hline 54 & 0.011 & 0.034 & 0.182 & 0.328 & 0.309 & 0.304 \\
\hline 55 & 0.011 & 0.044 & 0.191 & 0.341 & 0.293 & 0.309 \\
\hline 56 & 0.012 & 0.056 & 0.188 & 0.345 & 0.290 & 0.300 \\
\hline 57 & 0.012 & 0.063 & 0.191 & 0.345 & 0.283 & 0.300 \\
\hline 58 & 0.016 & 0.086 & 0.198 & 0.359 & 0.268 & 0.301 \\
\hline 59 & 0.018 & 0.252 & 0.203 & 0.417 & 0.263 & 0.284 \\
\hline 60 & 0.019 & 0.328 & 0.207 & 0.520 & 0.265 & 0.259 \\
\hline 61 & 0.021 & 0.408 & 0.215 & 0.565 & 0.263 & 0.254 \\
\hline 62 & 0.024 & 0.433 & 0.220 & 0.589 & 0.265 & 0.247 \\
\hline 63 & 0.028 & 0.453 & 0.225 & 0.602 & 0.283 & 0.247 \\
\hline 64 & 0.050 & 0.464 & 0.263 & 0.610 & 0.265 & 0.242 \\
\hline 65 & 0.080 & 0.382 & 0.338 & 0.616 & 0.250 & 0.259 \\
\hline 66 & 0.092 & 0.382 & 0.387 & 0.622 & 0.251 & 0.256 \\
\hline 67 & 0.100 & 0.390 & 0.389 & 0.620 & 0.254 & 0.245 \\
\hline 68 & 0.111 & 0.402 & 0.402 & 0.629 & 0.255 & 0.238 \\
\hline 69 & 0.121 & 0.406 & 0.400 & 0.630 & 0.246 & 0.231 \\
\hline 70 & 0.101 & 0.400 & 0.410 & 0.639 & 0.268 & 0.227 \\
\hline 71 & 0.103 & 0.385 & 0.418 & 0.647 & 0.260 & 0.226 \\
\hline 72 & 0.116 & 0.380 & 0.433 & 0.655 & 0.258 & 0.219 \\
\hline 73 & 0.128 & 0.374 & 0.439 & 0.659 & 0.253 & 0.214 \\
\hline 74 & 0.133 & 0.372 & 0.448 & 0.661 & 0.256 & 0.208 \\
\hline$\geq 75$ & 0.136 & 0.327 & 0.535 & 0.684 & 0.212 & 0.193 \\
\hline
\end{tabular}

Note: Authors' calculations based on the INPS Workers Archive and Pension Archive of outstanding pension benefits. This contains the universe of public pension benefits.

ther education). The choice of a ten-year interval is arbitrary and is based on a preliminary inspection of the data. ${ }^{15}$

15. It should be noted that, in order to gain variability in social security benefits, we did experiment with a larger sample including almost all workers, regardless of the existence of gaps in their careers. However, this did not add valuable information since the majority of workers with substantial spells out of the private sector would end up qualifying for minimum benefits (the level of which is fixed by legislation each year) or for an old-age income guarantee (pensione sociale). Hence, there would be very little correlation between earnings histories and pension benefits for these individuals, and the effects of potential reforms in changing the incentives to retire would be negligible (these workers would basically qualify for the minimum benefit under all regimes). Therefore, these cases would end up blurring the results rather than adding variability to be exploited. Finally, our choice of the ten-year threshold and the requirement of a five-year minimum presence in the archive gives us an estimated sample percentage of minimum benefit recipients that is not too far from what we observed in the universe of pension awards as recorded by the INPS Administration (see table 6.4). 
Distribution, by Labor Force Status in the SHIW

\begin{tabular}{lccccr}
\hline Year & $\begin{array}{c}\text { Private-Sector } \\
\text { Employee }\end{array}$ & $\begin{array}{c}\text { Public-Sector } \\
\text { Employee }\end{array}$ & Self-Employed & Pensioner & Other \\
\hline 1978 & 44.41 & 12.96 & 15.42 & 25.76 & 1.46 \\
1979 & 41.23 & 15.07 & 15.45 & 26.36 & 1.88 \\
1980 & 39.42 & 15.22 & 15.09 & 28.44 & 1.83 \\
1981 & 43.56 & 14.21 & 14.55 & 26.24 & 1.44 \\
1982 & 42.44 & 15.29 & 17.42 & 23.53 & 1.31 \\
1983 & 39.64 & 15.21 & 15.01 & 28.76 & 1.38 \\
1984 & 36.85 & 16.56 & 15.17 & 29.37 & 2.05 \\
1986 & 37.15 & 15.46 & 14.61 & 31.34 & 1.45 \\
1987 & 45.79 & 6.95 & 7.27 & 28.87 & 11.12 \\
1989 & 40.37 & 10.50 & 16.63 & 30.89 & 1.61 \\
1991 & 35.02 & 13.16 & 13.23 & 34.69 & 3.91 \\
1993 & 26.72 & 16.50 & 12.70 & 37.48 & 6.60 \\
1995 & 26.64 & 15.36 & 13.54 & 37.21 & 7.25 \\
Total & 37.00 & 13.69 & 13.80 & 31.39 & 4.12 \\
\hline
\end{tabular}

Notes: Private-sector employee $=$ active workers in private sector; public-sector employee $=$ active worker in public sector; self-employed $=$ a wide category of active workers working as entrepreneurs, professionals, and self-employed proper; pensioner $=$ self-reported pensioner.

In order to check the quality of our data, we carried out an extensive comparison between the basic variables in the INPS sample and those in the Bank of Italy's SHIW, using the whole sequence of SHIW cross sections for all available years between 1978 and 1995. Here we only report some of our results.

We look at changes in the composition of the workforce. Table 6.5 measures the relative importance of private-sector employees on total employment and shows a clear trend towards a reduced importance of employment in the private sector and a corresponding increase in the importance of self-employment and employment in the public sector. Hence, a drawback of the INPS data is that an increasingly important section of the workforce is not covered.

Turning to earnings of private-sector employees, notice that the SHIW only collects information on net earnings while the INPS data provide gross earnings figures (as earnings are recorded by the social security administration before any tax due). To carry out the comparison, the SHIW data were "grossed-up" using a procedure based on the information available at both the individual and the household level. There exist some differences in average gross earnings between the two samples: a more careful comparison was carried out by controlling for age and cohort effects. In particular, we estimated a simple model of gross earnings as a function of age and birth cohort, with synthetic cohorts defined according to the year of birth of each worker. This analysis confirmed a substantial agreement 
in the earnings data for the two samples, both the grossing-up procedure adopted for SHIW and the different sampling frame could partly explain the remaining differences.

\subsubsection{Earnings Projection}

The information needed in order to model age-earnings profiles in the INPS sample consists of age, gender, occupation, sector of employment, and region of working activity. ${ }^{16}$

The specification of a model for the age-earnings profile represents an essential step in the estimation of social security wealth at the individual level. This is especially important in Italy, as the process of social security reform involves moving from a final-salary type of benefit formula (pre1993 system) to a lifetime-earnings formula (1992 reform) and to a formula based on the value of lifetime contributions (1995 reform). ${ }^{17}$ We subsequently describe two additional hypothetical reforms that also involve extending the benefit calculation period. It turns out that results are very sensitive to the way that earnings projections, backward projections in particular, are carried out. For example, what may seem a negligible overestimation of real earnings in the early years can have marked effects on benefit calculations in the 1995 reform, where the whole earnings history matters and revaluation of past earnings is based on a five-year moving average of past GDP-growth rates.

Three alternative earnings-modeling strategies were considered. In the first strategy, individual real age-earnings profiles are assumed to be completely flat after the last year of observed earnings. This corresponds to the assumption that, at the individual level, the real-earnings process is a random walk with no drift. In practice, the "jump-off" point for the earnings projections is taken to be the average of the last three years of observed earnings. This jump-off point pins down the level of the age-earnings profile for each individual. ${ }^{18}$ Note that this might seem to underestimate future earnings growth, particularly for younger cohorts, but since our "sample at risk" (as defined later) consists mainly of older cohorts, the problem may not be too severe. ${ }^{19}$ Furthermore, for ages above fifty, earnings are lower on average and very noisy, possibly because of part-time work or the coexistence of early retirement benefits and working activities. When going back-

16. This is actually the region where the firm is located. Hence a comparison with the SHIW and national accounts data reveals that there seems to be a higher number of workers located in the northwest, where many large firms have their headquarters.

17. In this and the following sections, we only describe results for the 1995 reform; results for the other cases are available upon request from the authors.

18. When going backward, the jump-off point corresponds to the average of the first three observations available for each individual.

19. The cohorts at risk are defined according to year of birth: For the oldest cohort, these are birth years between 1918 and 1926, for the next cohort 1927-1936, and for the youngest cohort 1937-1944. 
ward, using a flat earnings profile would grossly overestimate the level of earnings at earlier ages and grossly underestimate real earnings growth. To avoid this problem, individual earnings were assumed to grow at the annual growth rate of aggregate earnings, for the years when this information is available, and at a constant real rate of 1.5 percent otherwise. ${ }^{20}$

In the second strategy, real earnings are projected into the future using group-specific growth rates obtained from the available sample, with groups defined by sex, age, birth cohort, and occupation. We did not really pursue this route, as some major drawbacks soon became apparent. Because group-specific growth rates are obtained using the sample information, we face the problem that individual-specific growth rates may differ dramatically from those estimated for the relevant group, but at the same time, group-specific growth rates may differ substantially from the macroeconomic growth rate. In addition, for younger cohorts we would often get very high growth rates going backward and very low growth rates going forward. Finally, notice that our first data point is in 1973 although we need to go back to the 1930s for some of our workers in order to complete their working history. Hence, we would be forced to use a hybrid procedure, which makes use of aggregate growth rates when projecting backwards into the distant past, while using group-specific growth rates for the recent past.

In the third strategy, real earning projections are obtained using a first order autoregressive process (AR[1]) specification. This estimation procedure did not give satisfactory results in terms of forecasting future earnings. For all these reasons, we opted for the first solution, which seems to be the safest. Notice that in projecting earnings forward, individuals are assumed to form expectations by using the model-in other words, for each age, we only use actual earnings up to that age and project earnings from that age forward according to the forecasting model.

\subsubsection{Transitions into Retirement}

The INPS sample contains no information on the reasons for leaving the archive. Thus, in order to use these data, we have to make the strong assumption that every exit from the archive is due to retirement. In fact, rather than retiring, a worker could have died or moved from private-sector employment to public-sector employment or to self-employment. Our identifying assumption is that, for the range of ages that we consider (from age fifty to sixty-five), exit from the INPS archive is due to retirement and not to other reasons.

This assumption is backed up by what we observe in the SHIW sample, which has available the full set of information concerning the occupational

20. Aggregate earnings are equal to the earnings series put together by Rossi, Sorgato, and Toniolo (1993) for the years before 1970 and to national account statistics for subsequent years up to 1999 . 
Table 6.6

Transitions Observed in the SHIW Panel Sample, by Age (\%)

\begin{tabular}{cccc}
\hline Age & $\begin{array}{c}\text { From Work } \\
\text { to Retirement }\end{array}$ & $\begin{array}{c}\text { From Work } \\
\text { to Disability }\end{array}$ & $\begin{array}{c}\text { From Disability } \\
\text { to Retirement }\end{array}$ \\
\hline 50 & 6.11 & 0.27 & 0.27 \\
51 & 11.79 & 0.00 & 2.85 \\
52 & 10.12 & 0.77 & 0.00 \\
53 & 9.03 & 0.28 & 0.00 \\
54 & 2.22 & 0.56 & 0.85 \\
55 & 15.03 & 1.12 & 0.56 \\
56 & 17.46 & 1.04 & 0.78 \\
57 & 20.16 & 0.25 & 1.03 \\
58 & 32.65 & 0.53 & 1.59 \\
59 & 22.07 & 0.00 & 1.91 \\
60 & 18.51 & 0.28 & 1.41 \\
61 & 15.78 & 0.50 & 2.79 \\
62 & 36.66 & 0.00 & 2.08 \\
63 & 40.74 & 0.00 & 1.51 \\
64 & 76.47 & 0.22 & 1.83 \\
\hline
\end{tabular}

status in each year. ${ }^{21}$ Table 6.6 shows the transitions observed in the panel component of the SHIW sample for the years 1989, 1991, 1993, and 1995. Each entry of the table gives the proportion of transitions as a percentage of the observations in that age group starting from the sample of workers in 1989. First, it is apparent that, after age fifty-four, the transitions into retirement are substantial. Furthermore, the overwhelming majority of transitions are from work to retirement, very few cases of transitions from work to disability are observed and only some cases from disability to retirement. ${ }^{22}$ We do not report transitions from retirement back into the labor force as these are basically nonexistent, and we can safely assume that retirement is an absorbing state.

This evidence suggests that, for Italian workers, the only relevant alternative escape route from the labor force is via disability. Many other "softlanding" or bridging plans exist, but they would all fall in the category of preretirement or early retirement, and in our data, they would effectively correspond to retirement. ${ }^{23}$ As far as disability benefits are concerned, after the changes legislated in 1984, their importance as an escape route has greatly diminished. ${ }^{24}$ This is shown quite clearly in figure 6.3 , which pre-

21. In the SHIW sample, different definitions of pensioner are available based on selfreported occupational status, on earnings, and on benefits receipts. However, no marked difference in the distribution of retired people by age emerged from adopting different definitions.

22. A disability pension is automatically converted into an old-age pension when the recipient reaches the age of eligibility.

23. For example, in the SHIW sample we do know about disability insurance, but early retirement and preretirement are recorded as retirement.

24. The fall in disability benefits out of total benefits occurring after 1984 is documented in Brugiavini (1999). 


$$
\begin{aligned}
& + \text { old-age } \\
& \text { o survivors' }
\end{aligned}
$$
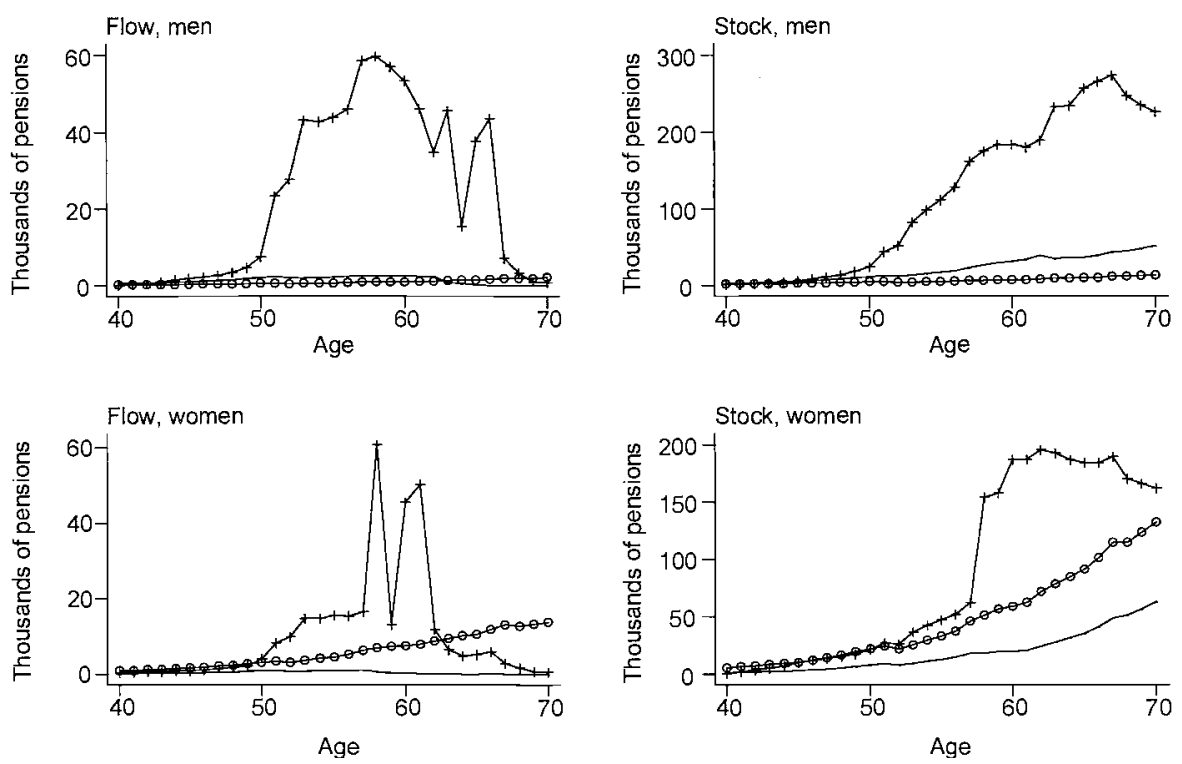

Fig. 6.3 Flow of new pensions in 1997 and stock of existing pensions at the end of 1997 (in thousands) by sex and age of the beneficiary and type of pension

Note: Figures are based on the INPS Archive of Outstanding Pension Benefits. This contains the universe of public pension benefits.

sents the number of new pension awards in 1997 (flow data) and the number of outstanding pensions at the end of 1997 (stock data). The data, kindly provided by ISTAT, are tabulations based on the INPS Pensions Archive and are broken down by sex and age of the beneficiary and by type of pension (old-age and early retirement, survivors, and disability). ${ }^{25}$ In the age range that we consider-fifty to seventy - the number of disability pensions is clearly negligible relative to old-age pensions, especially in the case of new awards (flow data). Disability becomes important relative to old-age pensions only if we consider the stock of pensions at ages above sixty-five, which reflects the very generous policy followed until the mid1980 s, a period that we do not model in this paper.

Finally, figure 6.4 presents two descriptions of the retirement hazard based on the INPS sample. The first is a nonparametric estimate based on the raw data, which shows sharp peaks at age sixty and age sixty-five and

25. The INPS pensions archive contains all outstanding pensions paid out by the INPS fund and by the other public funds, including the public-sector employees fund and the local authorities employees fund. This archive contains the universe of all public pension benefits. 
A

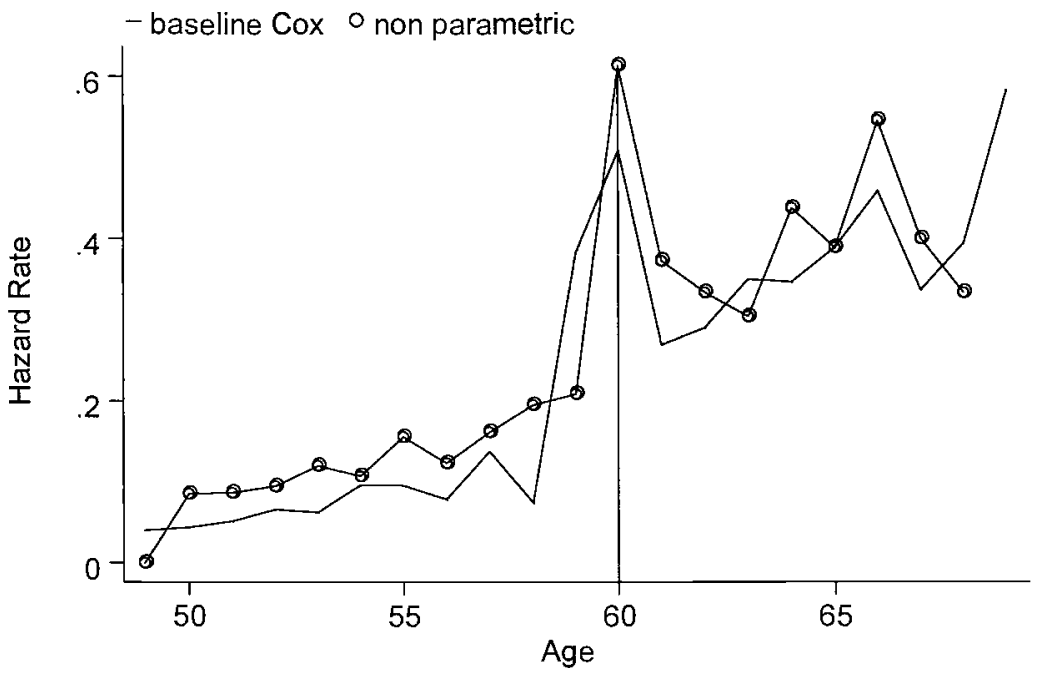

B

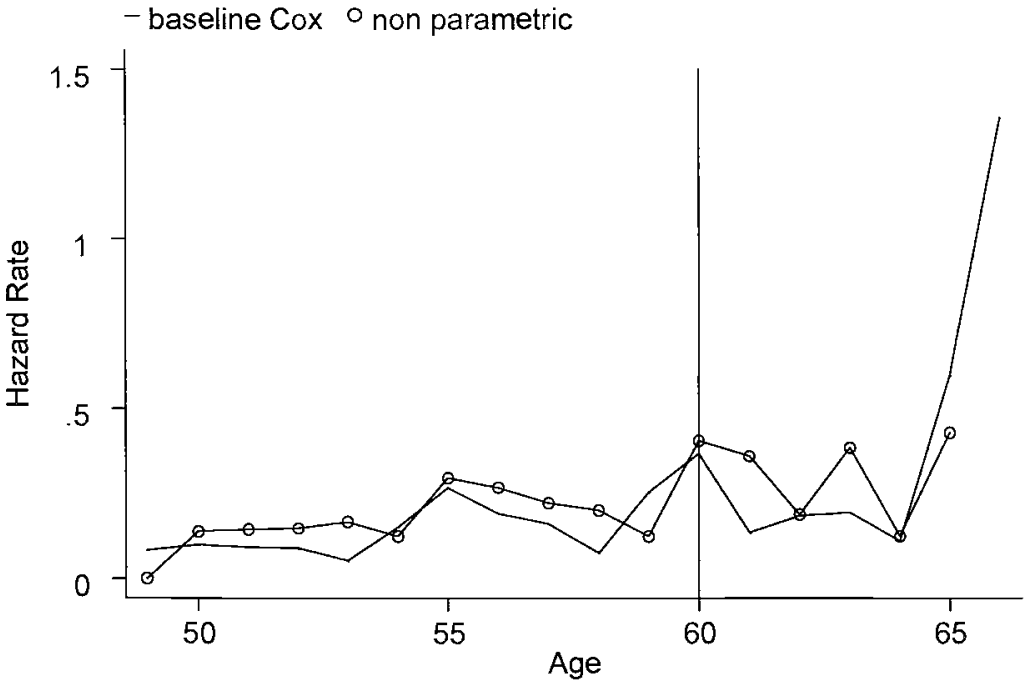

Fig. 6.4 Hazard functions: $A$, Men; $B$, Women

Note: Each picture shows two hazard functions. The nonparametric hazard is the one obtained from the raw hazard by simply relating the flow into retirement at each age to the stock of workers of that age. The baseline Cox hazard is obtained by using Cox proportional-hazard model with age as the only explanatory variable.

substantial exit already at age fifty. The second is a semiparametric estimate of the baseline hazard in a proportional hazard model with a number of basic demographic variables introduced as covariates that proportionally shift the baseline hazard. For men there is an important spike at age sixty, but a lot of action also at other ages, whereas for women there are sev- 
eral important ages at which the conditional probability of leaving the labor force peaks.

\subsection{Social Security Wealth and Incentive Measures}

Section 6.4.1 reminds the reader of the definition of social security wealth and the related incentive measures used in the econometric application. Section 6.4.2 lists our basic assumptions in the calculation of social security wealth, whereas section 6.4.3 describes the social security regimes modeled in the simulations.

\subsubsection{Definition of Social Security Wealth and Incentive Measures}

For a worker of age $a$, we define social security wealth (SSW) in case of retirement at age $h \geq a$ as the expected present value of future pension benefits

$$
\mathrm{SSW}_{h}=\sum_{s=h+1}^{S} \rho_{s} B_{s}(h),
$$

where $S$ is the age of certain death, $\rho_{s}=\beta^{s-a} \pi_{s}$ is a discount factor that depends on the rate of time discount $\beta$ and the survival probability $\pi_{s}$ at age $s$ conditional on being alive at age $h$, and $B(h)$ is the pension benefit expected at age $s \geq h+1$ in case of retirement at age $h$. Pension benefits are net of income taxes. Given the SSW, we define three incentive measures for a worker of age $a$.

First, social security accrual (SSA) is the difference in SSW due to postponing retirement from age $a$ to age $a+1$,

$$
\mathrm{SSA}_{a}=\mathrm{SSW}_{a+1}-\mathrm{SSW}_{a}=\sum_{s=a+2}^{S} \rho_{s}\left[B_{s}(a+1)-B_{s}(a)\right]-\rho_{a+1} B_{a+1}(a) .
$$

The SSA is negative if the expected present value of pension benefits foregone by postponing retirement by one year is greater than $\Sigma_{s=a+2}^{S} \rho_{s}\left[B_{s}(a+\right.$ 1) $-B_{s}(a)$ ], the expected present value of the increment in the flow of pension benefits. The rescaled negative accrual $\tau_{a}=-\mathrm{SSA}_{a} / W_{a+1}$, where $W_{a+1}$ are expected net earnings at age $a+1$ based on the information available up to age $a$, is called the implicit tax or subsidy of postponing retirement from age $a$ to age $a+1$.

Second, peak value is $\mathrm{PV}_{a}=\max _{h}\left(\mathrm{SSW}_{h}-\mathrm{SSW}_{a}\right), h=a+1, \ldots, R$, where $R$ is the mandatory retirement age (the latter does not exist in Italy, but given the retirement evidence, we find it reasonable to put $R$ equal to 70 ). Thus, the peak value is the maximum difference in SSW between retiring at future ages and retiring at the current age.

Third, option value is $\mathrm{OV}_{a}=\max _{h}\left(V_{h}-V_{a}\right), h=a+1, \ldots, R$, where

$$
V_{a}=\sum_{s=a+1}^{S} \rho_{s}\left[k B_{s}(h)\right]^{\gamma}
$$


is the intertemporal expected utility of retiring at age $a$, while

$$
V_{h}=\sum_{s=a+1}^{h} \rho_{s} W_{s}^{\gamma}+\sum_{s=h+1}^{S} \rho_{s}\left[k B_{s}(h)\right]^{\gamma}
$$

is the intertemporal utility of retiring at age $h>a$. Thus, the option value is the maximum utility difference between retiring at future ages and retiring at age $a$. We parameterize the model by $\gamma$ equals 1 and $k$ equals 1.25 . Under these assumptions, $V_{a}=1.25 \mathrm{SSW}_{a}$ and

$$
V_{h}=\sum_{s=a+1}^{h} \rho_{s} W_{s}^{\gamma}+1.25 \mathrm{SSW}_{h} .
$$

If expected earnings are constant at $W_{a}$ (as assumed in our earnings model), then

$$
V_{h}-V_{a}=W_{a} \sum_{s=a+1}^{h} \rho_{s}+1.25\left(\mathrm{SSW}_{h}-\mathrm{SSW}_{a}\right) .
$$

That is, the peak value and the option value are proportional to each other except for the effect due to the term $\sum_{s=a+1}^{h} \rho_{s}$.

These three incentive measures are consistent with the view that, in deciding whether or not to retire, a worker compares the expected gain from each of the two alternatives. Note that, in computing the incentive measures, we used the assumption that workers revise their expectations at each age. Hence for each given age, a worker projects the path of observed earnings according to the model and then computes their SSW and the incentive variables, taking into account the information currently available. This requires recomputing SSW and the corresponding incentive measures for each year until retirement. Reforms are assumed to come as a surprise to workers.

As is clear from the above formula, the social security accrual depends crucially on the expected present value $\rho_{s}\left[B_{s}(a+1)-B_{\mathrm{s}}(a)\right]$ of the increment in pension benefits at age $s$ resulting from postponing retirement by one year. Let $t$ denote the number of years of contributions for a worker of age $a$, and assume that pension benefits remain constant in real terms. Under the pre-1993 regime (but also during the transitional period that we assume as the baseline regime), if $t<40$ then

$$
B_{s}(a+1)-B_{s}(a)=0.02 t[\bar{W}(a+1)-\bar{W}(a)]+0.02 \bar{W}(a+1),
$$

where $\bar{W}(a)$ denotes pensionable earnings in case of retirement at age $a$; whereas if $t \geq 40$, then

$$
B_{s}(a+1)-B_{s}(a)=0.8[\bar{W}(a+1)-\bar{W}(a)] .
$$

In the special case when $\bar{W}(a+1)=\bar{W}(a)=\bar{W}$, we obtain

$$
B_{s}(a+1)-B_{s}(a)=\left\{\begin{array}{l}
0.02 \bar{W}, t<40 \\
0, \text { otherwise. }
\end{array}\right.
$$


Under the 1995 reform, we instead have

$$
B_{s}(a+1)-B_{s}(a)=\gamma(a+1) M(a+1)-\gamma(a) M(a),
$$

where $\gamma(a)$ represents the legislated conversion factor used to transform the worker's "notional account" into a pension annuity, and $M(a)$ denotes the value of such a notional fund in case of retirement at age $a$. If the fiveyear moving average of GDP growth rates (used to capitalize past earnings $)$ is positive, then the difference $\left[B_{s}(a+1)-B_{s}(a)\right]$ is always positive because $M(a+1)>M(a)$ and $\gamma(a+1) \geq \gamma(a)$, (with equality for $a>65$ ).

Note that, for many ages and under most regimes, SSW is a monotonically decreasing function of age. In all these cases, the maximum value of SSW over current and future years is attained at the current age. Therefore, once the eligibility criteria are met, the age profile of the peak value looks very similar to the age profile of the accrual. This explains why the pictures portraying the age profile of the peak value and the accrual look often similar (see section 6.4.2). We do have cases, however, of local maxima (e.g., under the 1995 reform).

\subsubsection{Basic Assumptions and Calculation of Social Security Wealth}

In the actual calculation of SSW, we assume a real discount factor of 1.5 percent ( $\beta$ equals 0.985 ). Benefits are defined in real terms and the indexation rules prevailing under each legislation are implemented (e.g., before the 1992 reform, we apply indexation to both price inflation and real wages). We also assume that real earnings growth after 1994 (the last year of the INPS sample) is constant at 1.5 percent. We carry out calculations as follows.

1. We estimate SSW for men and women separately.

2. Unlike most other countries in this project, we assume that workers are single. In fact, from the data, we are unable to tell whether or not a worker has a spouse. In the Italian legislation, the only major difference between a single worker and a married worker is eligibility to survivors' pension (there is no dependent-spouse benefit ${ }^{26}$ ). We did not attempt an imputation procedure to assign workers a spouse. ${ }^{27}$

3. Disability benefits have not been taken into account because multiple exit routes are not relevant in the Italian case. We experimented with

26. There is a difference in the rebates on income tax and in the calculation of minimum benefit, particular in the way in which means testing is carried out.

27. We could readily generalize our calculations to include pensions to a surviving spouse. For example, we could randomly assign to men a wife who is three years younger. However, this imputation would not produce extra variability in SSW, because pension wealth of survivors depends on the characteristics of the deceased and on the survivor's age. Hence, in order to have an impact on the variability of the profile of SSW by age, we should also assign randomly the age of the imputed wife, which may produce a considerable amount of noise for a little gain. 
adding this alternative exit route in an ad hoc fashion by using the observed disability probabilities, but this had no effect on the main findings.

4. We do not account for the lump-sum benefit represented by the TFR, since the paper by Brugiavini (1999) shows that this lump sum benefit does not alter dynamic incentives.

5. We assume variation in mortality only by sex and age.

6. We look at all individuals considered at risk (i.e., aged fifty to seventy).

Note that, in our sample, the first worker who becomes eligible for retirement under the baseline regime is aged fifty, and the econometric application makes use of the full range of ages between fifty and seventy. However, since there are very few exits until age fifty-two and very few individuals working after age sixty-five, in some tabulations (e.g., table 6A.1 in the appendix) we present results starting at age fifty-three and group in a single age interval all workers aged sixty-five and over.

In estimating the model, we also had to deal with the fact that the actual age of entry into the labor market is not always known. We used the information on the initial occupational level to get a reasonable proxy for educational attainments. This was then used to impute an initial age for the worker's contributive history.

Eligibility rules and benefit computation rules prevailing under each regime are rather complex (see section 6.2), and some shortcuts were made. Finally, we computed SSW net of income tax, by subtracting from gross pension benefits income taxes as due.

\subsubsection{Social Security Regimes Modeled in the Simulation}

We estimate SSW and incentive variables under five alternative regimes: ${ }^{28}$

1. The rules prevailing before 1993;

2. The rules actually prevailing during the transitional phase that starts in 1993, and this case represents our baseline;

3. The rules prevailing in the steady state, once the 1995 reform is fully phased in;

4. Policy simulation 1 in which, starting from the current system (the baseline case), we raise the normal retirement age by three years while holding constant all other features; and

5. Policy simulation 2, which entails a different pension program altogether that features an early retirement age of sixty and a normal retirement age of sixty-five. It provides a retiree with a benefit replacing 60 per-

28. We actually also simulated the rules prevailing after 1992 in the steady state once the Amato reform is fully phased in. But, since this case is only of theoretical interest and the 1992 reform will never reach its steady state values as subsequent changes took place in 1995 and 1997, we did not report results for this case. 
cent of their projected earnings when they turn sixty-five. It applies an actuarial reduction of 6 percent per year for early claiming and an actuarial increase of 6 percent per year for later claiming. It essentially makes early retirement costly and introduces age neutrality in retirement choices.

To simplify the presentation, we only report the results obtained for the baseline, the 1995 reform, and the two policy simulations.

Table 6A.1 of the appendix presents descriptive statistics (mean, standard deviation, and selected percentiles) for the three incentive measures. In the baseline case, eligibility is reached very early and SSW tends to decrease monotonically after the eligibility age. By comparing the two initial panels of table 6A.1, one has a first impression of the effects of the 1995 reform: under the post-1995 regime, SSW becomes positive only late in life, and median SSW is lower. We also report descriptive statistics for the implicit tax on work, an incentive measure that was used extensively in Gruber and Wise (1999). On average, the estimated implicit tax in our sample is fairly close to the one obtained for a reference individual in the Gruber and Wise study. ${ }^{29}$ In particular, taking the comparable case of a single male worker under the pre-1993 legislation, the average implicit tax of the sample is in line with the one computed in Brugiavini (1999), but it differs substantially at the two crucial ages of sixty and sixty-five.

Figures 6.5 through to 6.8 complement this information by presenting nonparametric estimates of the density for each incentive measure and for SSW. This is done first under different policy regimes separately for men and women (figures 6.5 and 6.6) and then at selected ages for men only (figures 6.7 to 6.8 ). These estimates have been computed by the kernel method using only the observations with a positive value of the SSW. The effects of the reform on the density of the relevant variables produced by the policy simulation 1 (three-year delay) are negligible, and we do not report them in these graphs. The 1995 reform and the policy simulation 2 (actuarial adjustment) have a more marked impact. For men, both reforms imply a shift to the left of the distribution of SSW (see figure 6.5) and, hence, a lower mean and no substantial change in dispersion. However accrual and peak values show a substantial change in the level of concentration around the mean as a result of the reforms, while the option value exhibits an interesting bimodal shape. For women, as a result of the reforms, there are more important changes in the location and dispersion of all variables, including SSW. For men, we also look at the distribution of SSW and all incentive measures for a few selected ages. These distributions are much more sensitive to age under the baseline than under the reforms. This confirms the point that the pre-1993 legislation (essentially the baseline) was highly non-neutral with respect to age.

29. In the Gruber and Wise study (1999; see Brugiavini 1999 for Italy) the reference individual is basically a worker characterized by the median earnings of his cohort. 

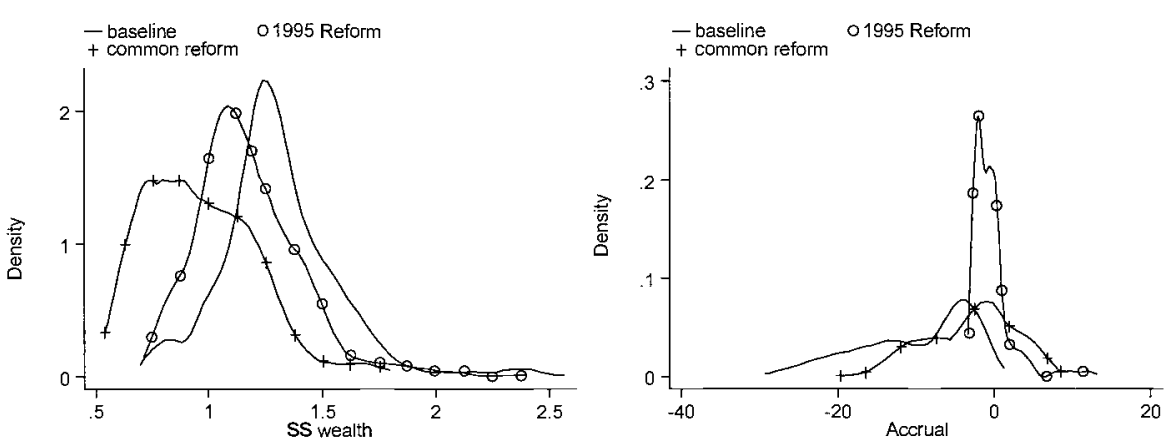

SSW, baseline vs reforms

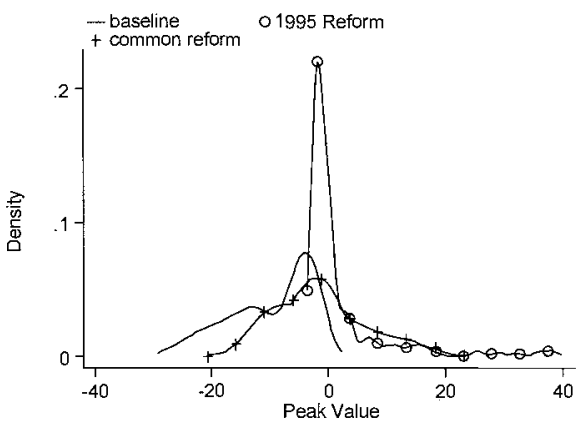

Peak value: baseline vs reforms

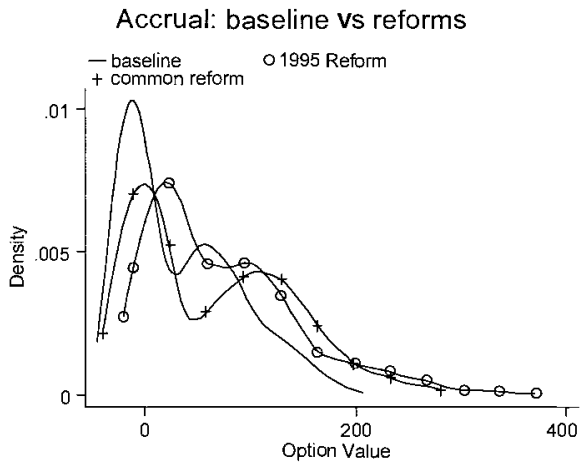

Option value: baseline vs reforms

Fig. 6.5 Kernel-estimated density of social security wealth and incentives (SSW in 1998 euro $\left.\cdot 10^{4}\right)$, men

Note: We do not show the results for the plus-three-years reform as these almost entirely overlap with the baseline densities.

\subsection{Modeling Retirement Choices}

In this section we present the results of modeling exit into retirement using probit models that include, in addition to a standard set of covariates (such as age, occupation, and sector), the incentive measures discussed in the previous section. Table 6.7 provides mean values and standard deviations of the relevant variables.

\subsubsection{Probability of Retirement}

We present two tables of probit estimates, one for men (table 6.8) and one for women (table 6.9). In either case, the response variable is a binary indicator, representing exit from the INPS sample between the year $t$ and the year $t+1$. As discussed in section 6.4, we assume that exit from the INPS sample corresponds to retirement. The population at risk consists of workers aged between fifty and seventy in any of the relevant years. The sample used for estimation includes all pairs of years from 1980 to 1981 

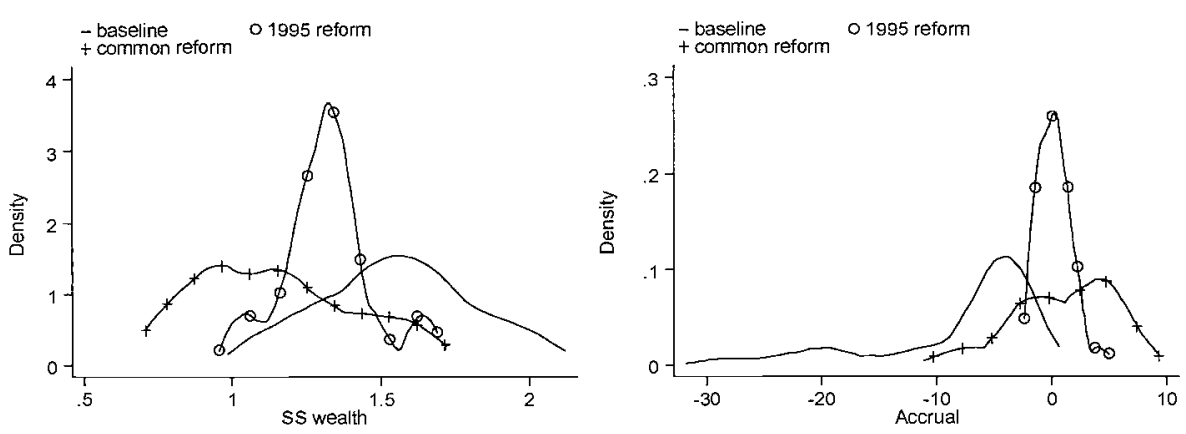

SSW, baseline vs reforms

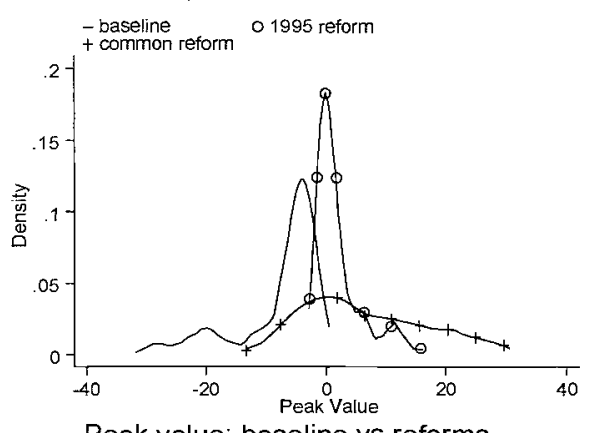

Accrual: baseline vs reforms

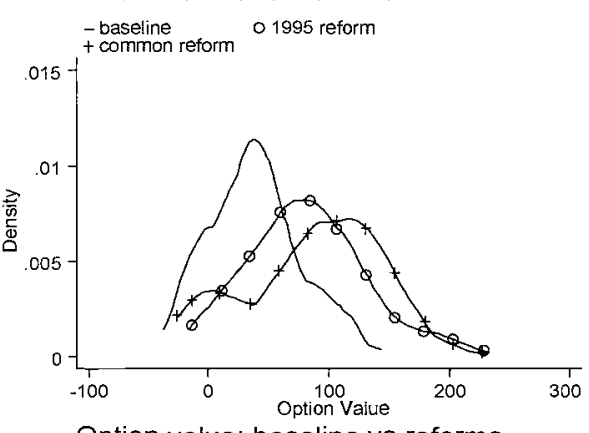

Peak value: baseline vs reforms

Option value: baseline vs reforms

Fig. 6.6 Kernel-estimated density of social security wealth and incentives (SSW in 1998 euro $\cdot 10^{4}$ ): Women

Note: We do not show the results for the plus-three-years reform as these almost entirely overlap with the baseline densities.

through 1993 to 1994 . Because in some cases we have to model earnings profiles going back fifty years, given the existing limitations on aggregate wage data, we restrict the analysis to individuals at risk after 1980. In this way, our oldest worker is aged seventy in 1980, and we only need to backcast earnings to the year $1930 .^{30}$

For each incentive measure, two basic specifications are considered for a total of six estimated models. The first column of each table corresponds to the use of the accrual as the incentive measure and shows the results obtained for a general specification that includes, in addition to accrual and SSW, a set of sectoral and regional indicators, a linear age term, and a set of earnings measures relevant for the retirement choice (i.e., a quadratic polynomial in expected earnings and a quadratic polynomial in pensionable earnings). It should be noted that, for all ages, expected earnings in the 

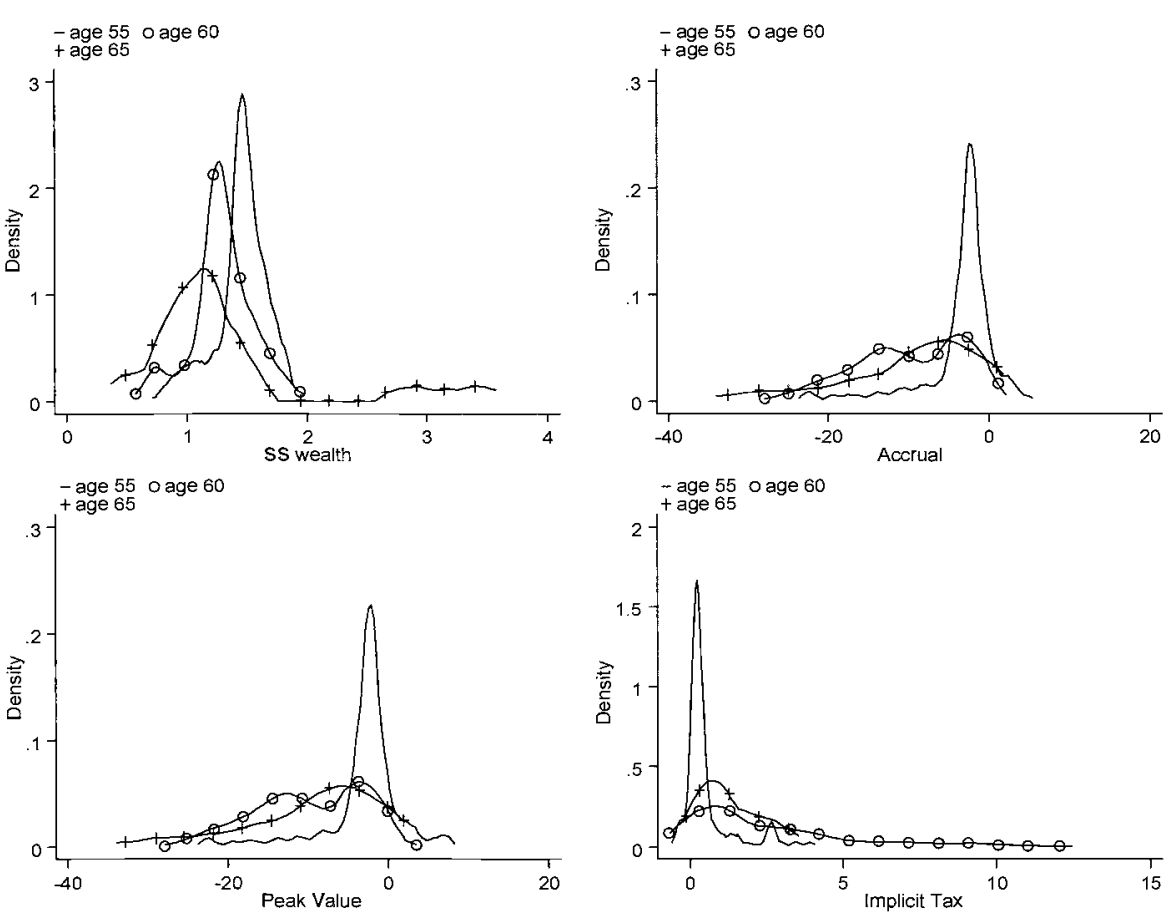

Fig. 6.7 Kernel-estimated densities, social security wealth, and incentives for selected ages: Men—baseline

next period are computed based on the projection model and the information available to the worker at that age. We refer to this as model M1. The second column shows the results for a specification in which the effect of age is modeled through a set of age dummies, rather than a linear age term, while the rest of the specification is unchanged; we refer to this as model M2. The same pattern is repeated for the other columns: columns (3) and (4) correspond to the use of the peak value with, respectively, a linear age trend (model M1) and a set of age dummies (model M2), while columns (5) and (6) correspond to the use of the option value. Since coefficients from a probit analysis do not have an immediate interpretation, we also provide the probability effect of the relevant variables. These are shown underneath the coefficient estimated for SSW and for each incentive variable. Since the scale of each of these variables differs, we measure the probability effect (for the reference individual) by increasing the variable of interest from the mean level to the level of the mean plus one standard deviation, holding the other variables constant.

In our baseline specification, SSW and all incentive measures are computed according to the transitional rules introduced after 1992. This represents the relevant regime for the workers in our sample. Overall, using 

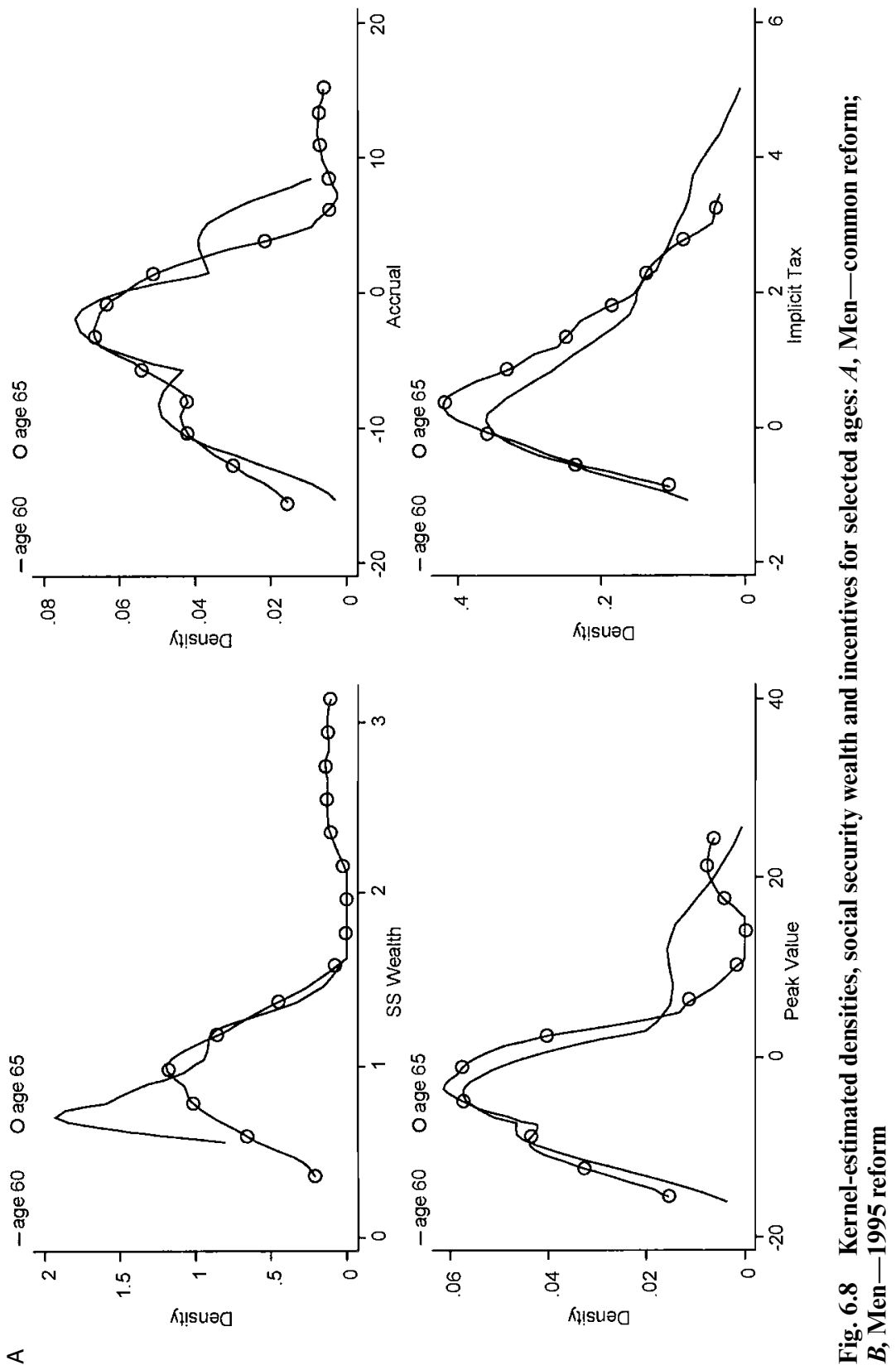

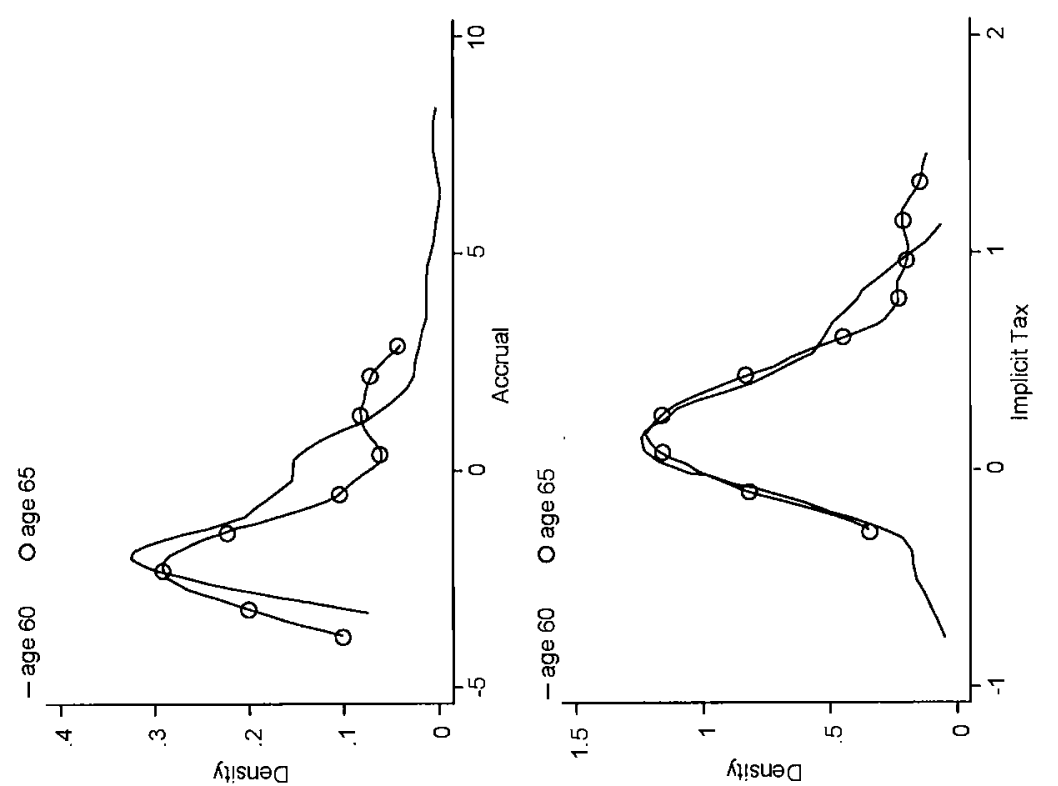

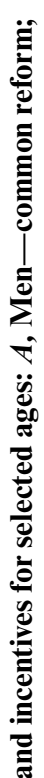

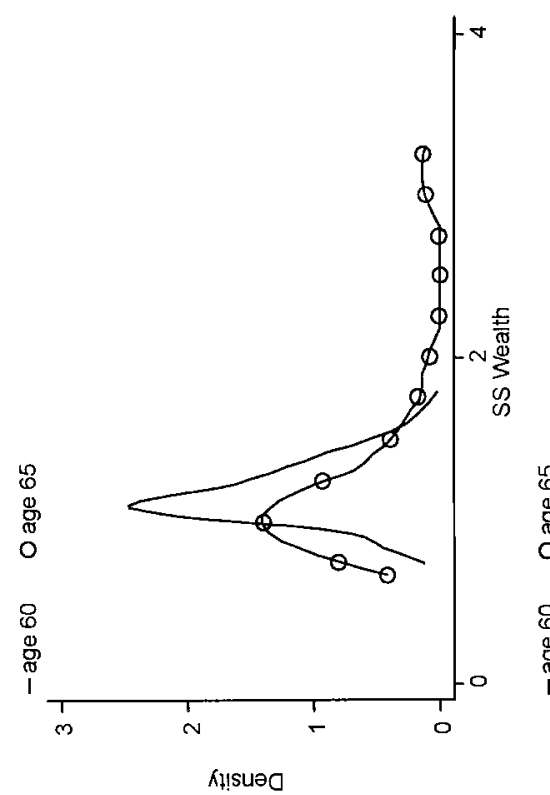

$m$

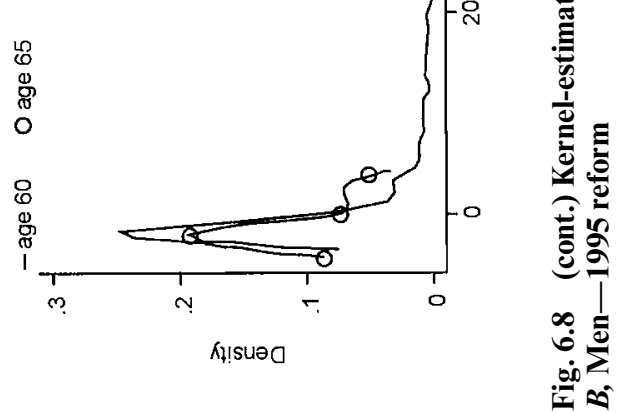




\begin{tabular}{|c|c|c|c|c|}
\hline \multirow[b]{2}{*}{ Variable } & \multicolumn{2}{|c|}{ Women } & \multicolumn{2}{|c|}{ Men } \\
\hline & Mean & SD & Mean & SD \\
\hline Year & 87.74 & 4.07 & 87.14 & 4.17 \\
\hline Age & 53.06 & 3.51 & 53.80 & 3.62 \\
\hline No. of jobs held & 0.58 & 1.11 & 0.91 & 1.58 \\
\hline Industry dummy & 0.47 & 0.49 & 0.50 & 0.49 \\
\hline Agriculture dummy & 0 & 0 & 0.01 & 0.10 \\
\hline Building dummy & 0.00 & 0.08 & 0.11 & 0.31 \\
\hline Trade dummy & 0.14 & 0.35 & 0.08 & 0.27 \\
\hline Transport dummy & 0.02 & 0.15 & 0.09 & 0.29 \\
\hline Financial dummy & 0.03 & 0.17 & 0.04 & 0.20 \\
\hline Other sector dummies & 0.30 & 0.46 & 0.14 & 0.35 \\
\hline Earnings & $13,736.26$ & 52.88 & $18,953.01$ & $14,495.15$ \\
\hline Years of contribution & 32.44 & 3.93 & 33.12 & 4.43 \\
\hline \multicolumn{5}{|l|}{ SSW } \\
\hline Baseline & 0.52 & 0.79 & 0.53 & 0.73 \\
\hline 1995-ref & 0.17 & 0.45 & 0.27 & 0.56 \\
\hline S1 & 0.22 & 0.56 & 0.25 & 0.55 \\
\hline S2 & 0.07 & 0.28 & 0.07 & 0.29 \\
\hline \multicolumn{5}{|l|}{ Option value } \\
\hline Base & 236.93 & 179.69 & 269.36 & 240.63 \\
\hline Ref & 312.23 & 176.62 & 343.64 & 260.39 \\
\hline S1 & 290.92 & 173.39 & 313.94 & 239.15 \\
\hline S2 & 306.90 & 162.65 & 335.34 & 232.58 \\
\hline \multicolumn{5}{|l|}{ Peak value } \\
\hline Baseline & 101.84 & 86.03 & 87.60 & 82.20 \\
\hline 1995-ref & 118.09 & 63.71 & 106.36 & 78.42 \\
\hline S1 & 137.40 & 72.49 & 115.64 & 74.77 \\
\hline S2 & 113.16 & 43.15 & 98.40 & 48.71 \\
\hline \multicolumn{5}{|l|}{ Accrual } \\
\hline Baseline & -2.00 & 7.27 & -2.02 & 6.32 \\
\hline 1995-ref & 0.27 & 1.36 & 0.34 & 2.51 \\
\hline S1 & -0.72 & 3.87 & -1.11 & 4.32 \\
\hline S2 & -0.01 & 1.75 & -0.15 & 2.85 \\
\hline Retirement dummy & 0.12 & 0.33 & 0.11 & 0.31 \\
\hline Northwest & 0.45 & 0.49 & 0.38 & 0.48 \\
\hline Northeast & 0.21 & 0.41 & 0.22 & 0.41 \\
\hline Center & 0.27 & 0.44 & 0.21 & 0.41 \\
\hline South & 0.04 & 0.19 & 0.11 & 0.32 \\
\hline Islands & 0.01 & 0.12 & 0.05 & 0.22 \\
\hline Blue-collar & 0.62 & 0.48 & 0.73 & 0.44 \\
\hline White-collar & 0.32 & 0.46 & 0.23 & 0.42 \\
\hline Manager & 0.00 & 0.07 & 0.03 & 0.17 \\
\hline Other levels & 0.04 & 0.20 & 0.00 & 0.04 \\
\hline
\end{tabular}

Note: $\mathrm{SD}=$ standard deviation. Earnings are in 1998 euros; $\mathrm{SSW}$ is in 1998 euro $\cdot\left(10^{6}\right)$. SSW and incentive variables are distinguished according to the baseline case, the 1995 reform, and the two hypothetical reforms. 


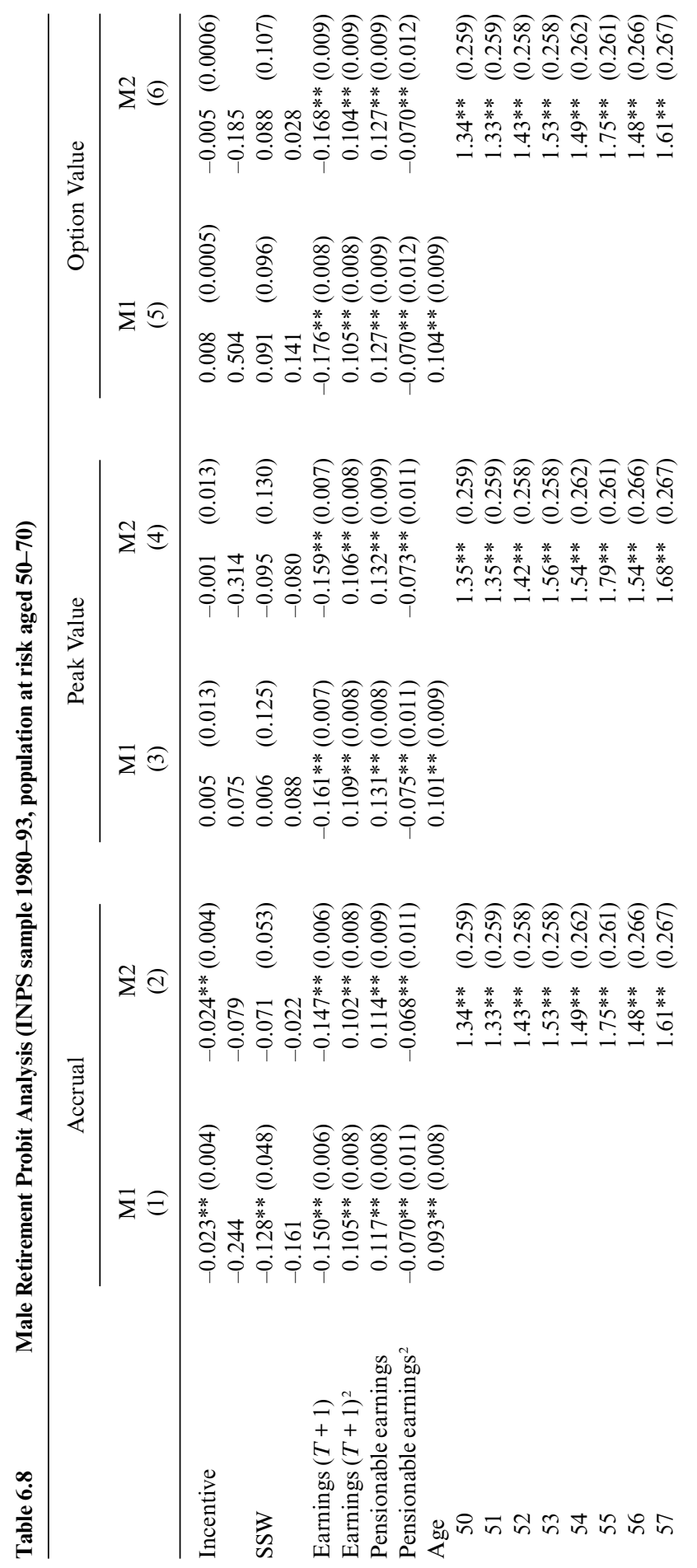




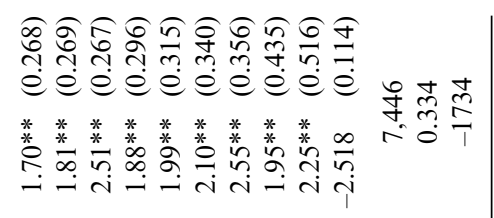

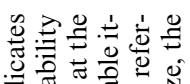
을

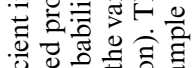

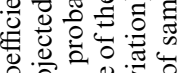
年

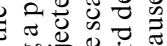

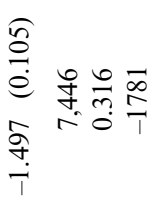

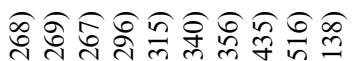
è é巳è é巳é巳e

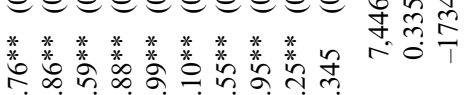

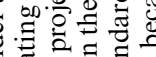

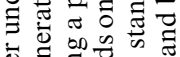

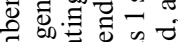

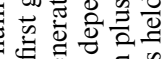

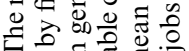
记

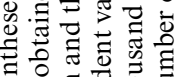

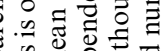

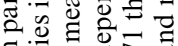
: t)

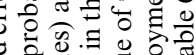

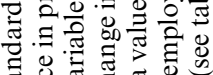

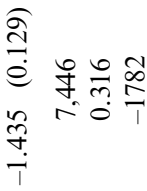

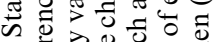

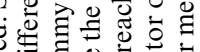

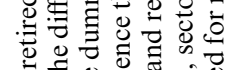
on

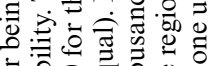

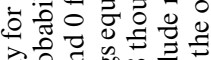
क्षे

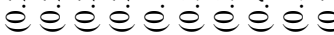

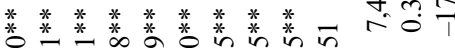

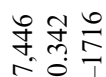

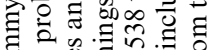
㛃

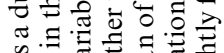
.

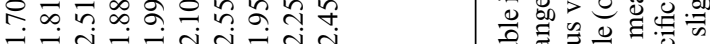

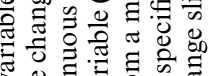

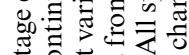

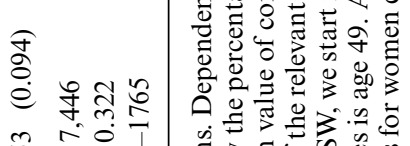

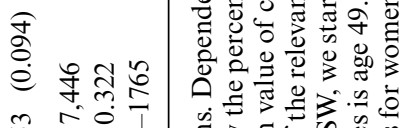

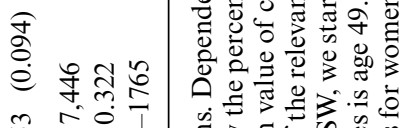
m

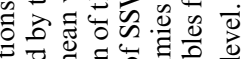

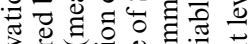

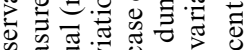

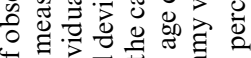


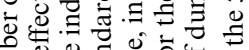

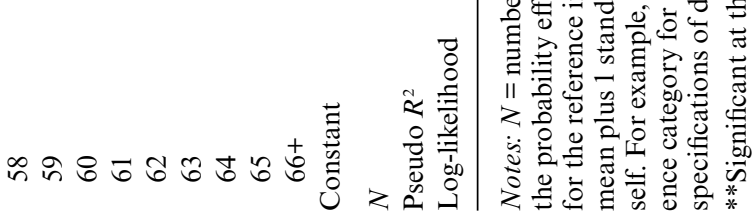

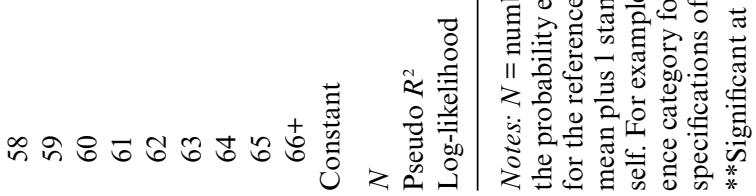




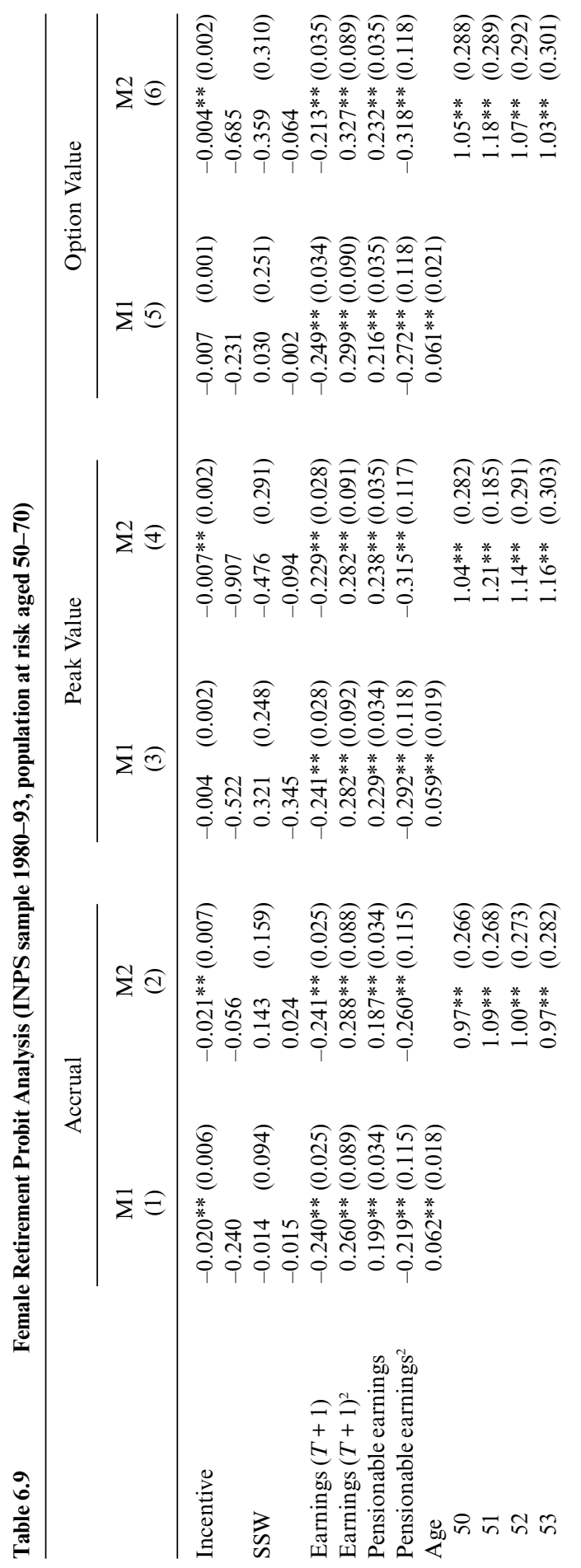




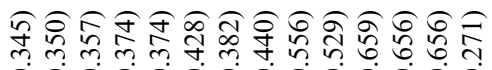

ระeverevecese.

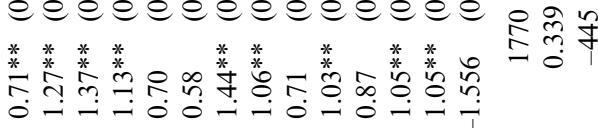

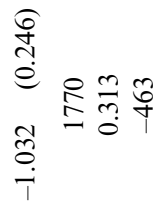

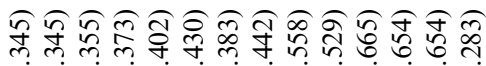

equecerecereo

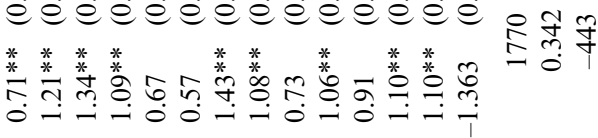

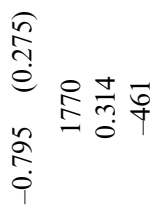

సิळ

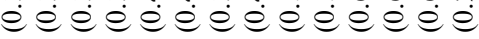

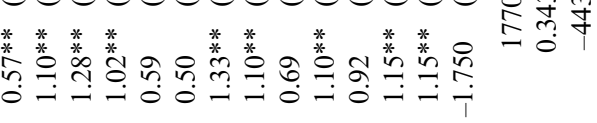

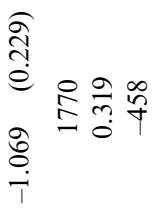

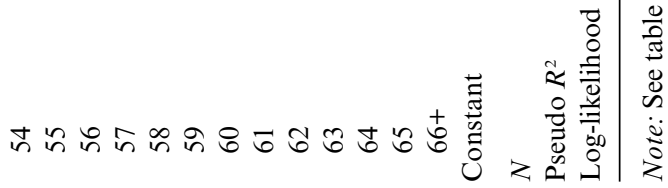


instead the pre-1993 rules leads to negligible differences in terms of SSW and eligibility for our sample of workers. This is because, as already mentioned, the rights of workers near retirement were changed only marginally by the reforms of the 1990s.

All the specifications are satisfactory in terms of explaining variability in the data, as indicated by pseudo $R^{2}$ values ranging between 32 and 34 percent. The use of age dummies increases the fit relative to the model with a linear age term, but only marginally. This suggests that age is an important determinant of retirement decisions but, despite the presence of impressive spikes in the hazard, we get only marginal gains by making use of a fully parameterized model. Hence, these spikes may be less important than they first appear in explaining the age-retirement process, as most of the action comes from the exits taking place between age fifty and age sixty. For men, the accrual is the only incentive variable that is statistically significant and has the expected negative sign. For women, instead, the incentive variables have the expected sign and are significant, at least for the specifications with age dummies. For the estimates based on the accrual, we also find a nonnegligible probability effect of the incentive variable (a one-percent increase in the accrual decreases the retirement probability by 24 percent). In some cases, SSW has a negative effect on retirement. This is somewhat surprising as it suggests that workers with higher levels of SSW tend to postpone retirement (i.e., have a taste for work) even after controlling for the type of job and the occupational sector. However, the negative coefficient is hardly ever significant.

A better grasp of the importance of the age effects can be gained by looking at figure 6.9. In the top part, we present results for the general model with age dummies (M2). We plot the raw hazard computed in the estimation sample versus the projected hazards both for men (left panel) and women (right panel). The projected hazards are obtained, on the basis of the general model M2 and for the baseline case, by setting the incentive variables and all continuous variables to their mean value and setting to zero all dummies, except the age dummies. The different lines drawn for the projected hazards on the same graph correspond to the different incentive measures.

Figure 6.10 compares the hazard function and the cumulative distribution function (CDF) of the raw data with those implied by our estimates of model M2 (the baseline). The raw hazard and the raw CDF have a number of interesting features. In particular, while the hazard shows significant spikes at age fifty-five and sixty for men (more spikes for women), it is clear from the CDF that half of the sample has already retired by age fifty-seven for men and by age fifty-five for women. The results obtained for the two models described above (models M1 and M2) suggest that the linear age term does not capture the important spikes in the data, but the use of a full set of age dummies provides an age profile for the hazard that is fairly close to the raw hazard, although at the cost of saturating the model. 


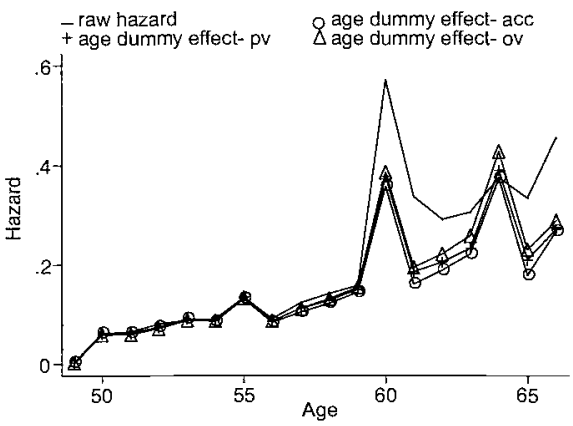

M2: age dummies effect, men

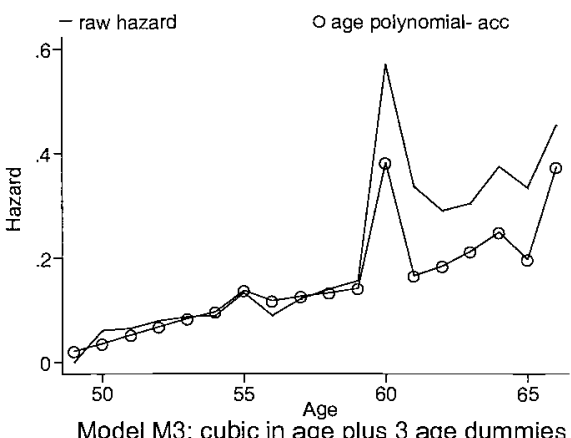

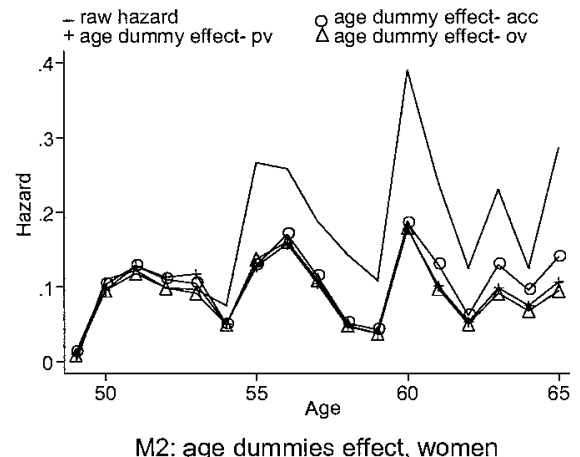

M2: age dummies effect, women

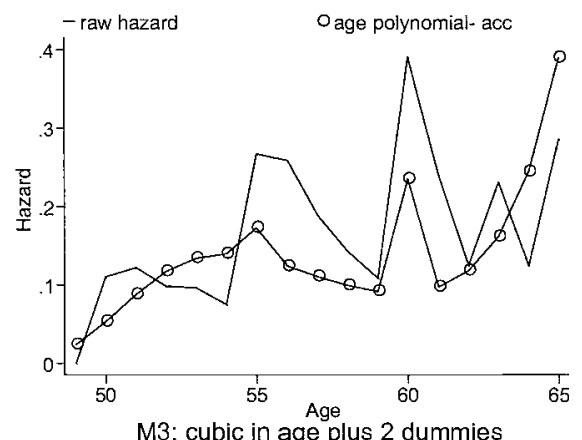

Fig. 6.9 Age effects in model M2 and model M3

Note: The left panels are for men and the right panels for women. The continuous line is the raw hazard. The estimated hazards are based (a) on the complete model M2 for each of the incentive variable (top panels) and (b) on the parsimonious representation based on a cubic in age plus the relevant dummies M3 (bottom panels). We convert in probability space the age effects for a representative worker. This worker is characterized by the mean values of continuous variables and zero for all the dummy variables (apart from age and age dummies). Results are based on estimation sample.

In order to separate the effect of age on retirement due to preferences from the age effect related to incentives and to provide a parsimonious representation of the age effects, we carry out an additional probit analysis in which we replace the linear age term by a combination of a cubic function of age-plus-three dummies at ages fifty-five, sixty, and sixty-five. ${ }^{31}$ This model, which we call model M3, tries to capture the fact that the raw hazard tends to increase smoothly with age, except for the presence of three important spikes at ages fifty-five, sixty, and sixty-five. We interpret the estimated cubic-age trend as the "pure" effect of preferences on retirement. The results of the probit analysis are not presented for the sake of brevity. We simply note that the main results obtained for model M2 remain valid for model M3 and that the age effects are significant overall. We use this specification M3 in two ways: (a) directly, to make projections on the basis

31. For women, only two age dummies at fifty-five and sixty are added. 

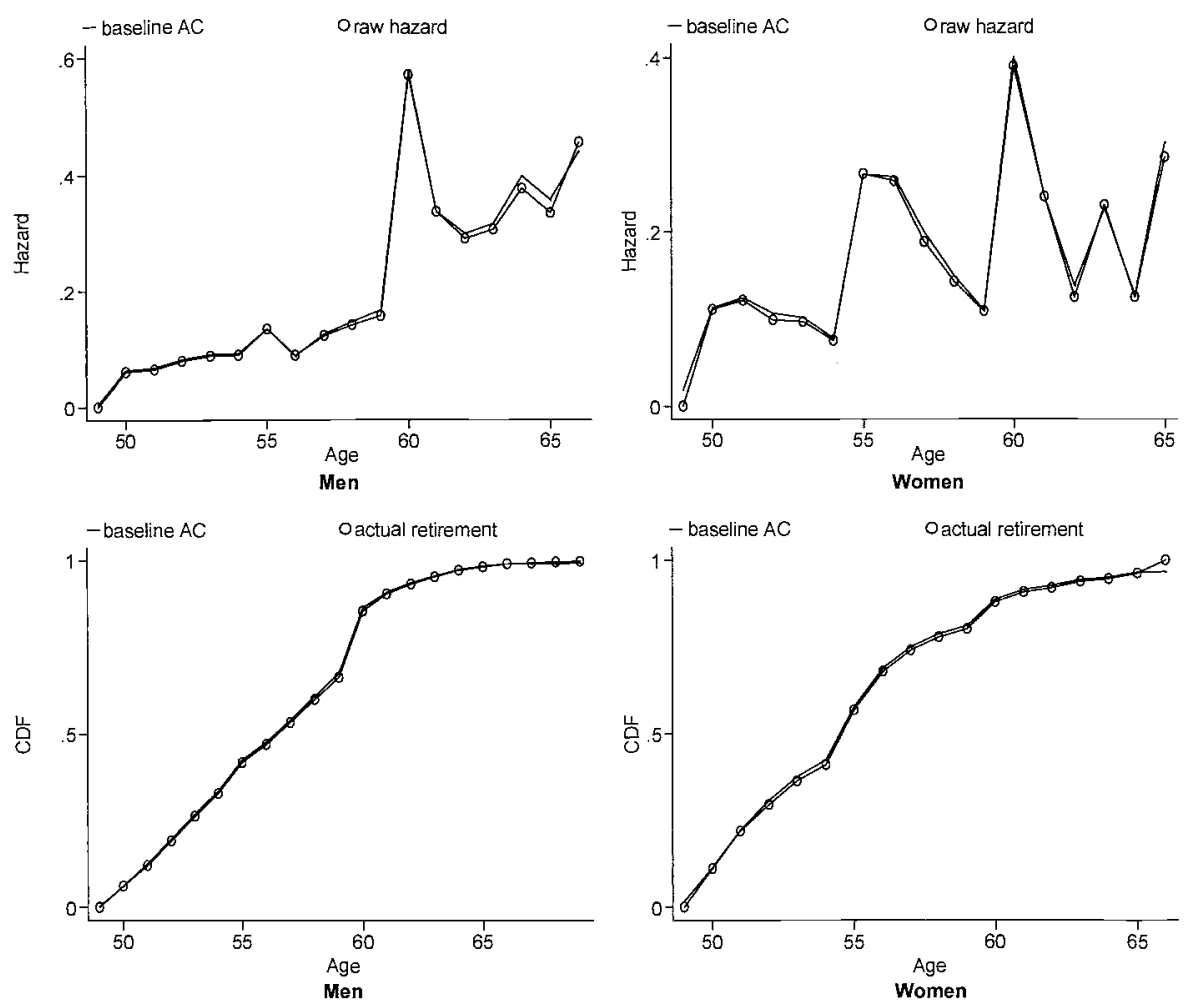

Fig. 6.10 Hazard and CDF: Raw data versus baseline estimates in model M2

Note: The top panels present the hazard functions while the bottom panels present the corresponding CDF. The results for the baseline are obtained from the general model M2. These graphs are based on the estimation sample (7,446 observations for men and 1,770 observations for women) where individuals drop from the sample at the age of actual retirement. The picture looks much different for the simulation sample, where individuals are assumed to be at risk up to a maximum age of seventy.

of an "intermediate" specification in simulating retirement decisions, and (b) indirectly, to impose the estimated age effect on the results of specification M2 in order to "purge" the effect of age-preferences from the general model M2. ${ }^{32}$ Results are described in figure 6.9 (bottom panels), where the age effects implied by model M3, along with the raw hazard, are graphed

32. By intermediate specification we mean one that models age in a satisfactory way without saturating the model. In view of the 1995 reform, which tries to implement an actuarially fair system, it would be reasonable to remove the three dummies and to allow the cubic specification in age to capture taste for retirement. However, in our sample, which does not cover the postreform years, we have a basic identification problem on the interpretation of the spikes occurring at particular ages, as these may be mostly due to legislation but could also emerge as a result of habits and peer effects in retirement choices. 
against age for both men and women. This specification fits closely the age pattern observed in the data, particularly for men.

\subsubsection{Simulating Retirement Choices}

We carry out simulations separately for men and women. This is done on a simulation sample in which earnings are projected forward as well as backward to cover the necessary time span, regardless of actual entry into the sample and of possible gaps in earnings. In all cases, we maintain the assumption that policy changes are not anticipated. We perform six types of simulations based on three policy variants to be contrasted with the baseline. The first policy variant envisages a forward shift of three years in the retirement ages. The second policy variant (referred to as the "common reform") consists of an actuarial adjustment of benefits of 6 percent per year and is designed to make early retirement costly to individuals. The last variant is the actual 1995 reform of the Italian social security system.

\section{Simulation S1 (Model MI)}

Starting from the model, which only includes a linear age trend (model M1), we project the estimated hazard on the simulation sample by changing the SSW and the incentive variables according to the chosen reform. Results for men are shown in figure 6.11 (accrual and peak value) and the left panels of figure 6.12 (option value). The effect of a policy change is significant only in the case of the accrual. The largest effect is under the common reform. Results are not much different for women (left panels of figure 6.14).

\section{Simulation S2 (Model M2)}

Starting from the model with age dummies (model M2), we project the estimated hazard by changing the incentive variables according to the chosen reform while leaving all the other variables (including the age dummies) unchanged. Since the model is saturated and the age dummies are very important in explaining variability in retirement probabilities, this case leaves little room for the effects of policies. Results are shown for men in figure 6.12 (right panels) and figure 6.13. The only case where the effect of a policy change is nonnegligible is for the accrual (figure 6.12 M2-S2 for men and figure 6.14 for women).

\section{Simulation S3 (Model M2)}

Starting from the model with age dummies (model M2), we project the estimated hazard by changing all the relevant variables (incentive variables and age dummies) according to the policy change. In this experiment we want to measure the impact of policies going through the incentives and through a direct effect of age, and hence it is important to net out the effect that age has on retirement due to individual preferences. To this end, in 

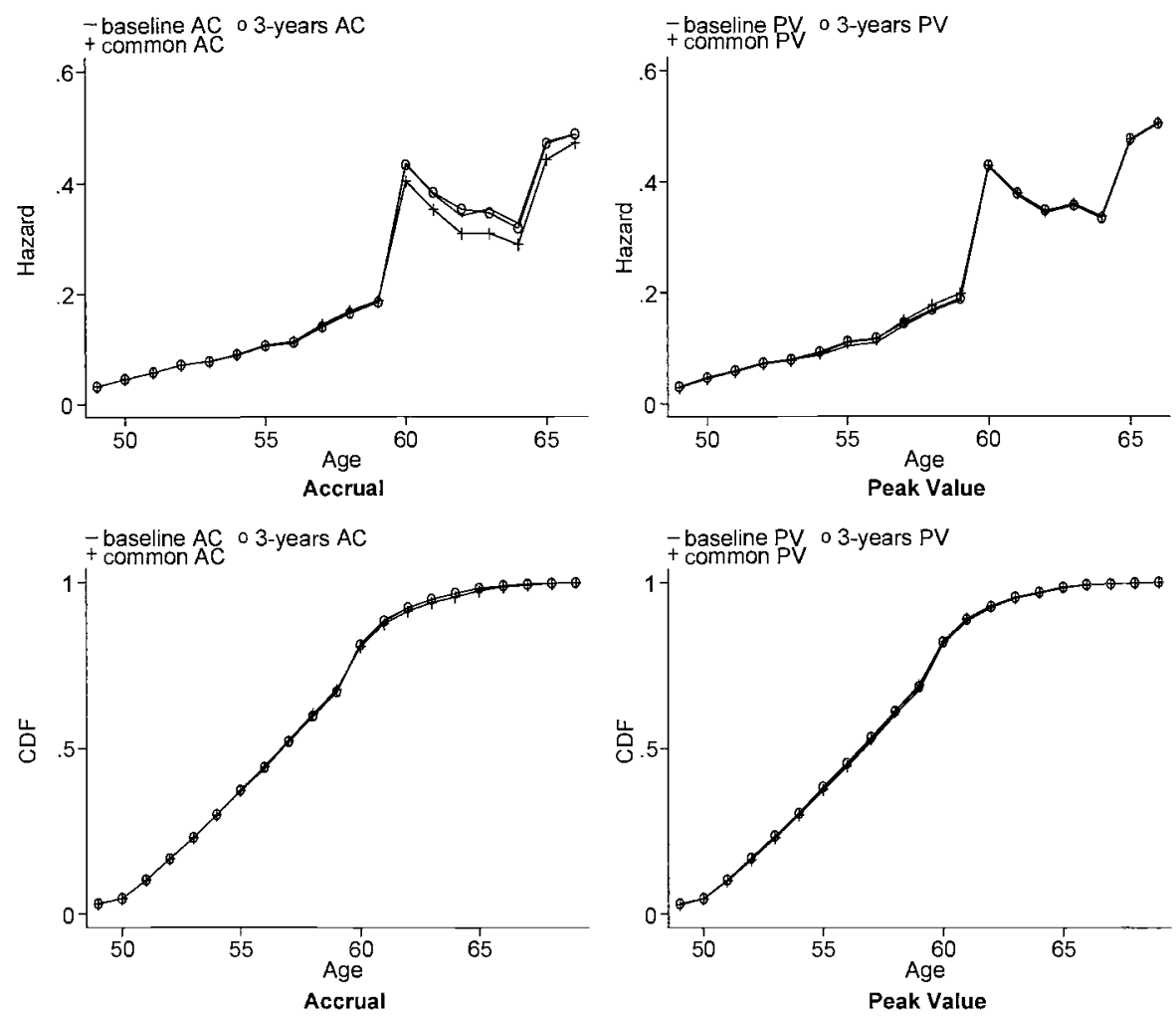

Fig. 6.11 Simulation M1-S1 for accrual and peak value, men

Note: The top panels show the hazards and the bottom panels the corresponding CDF. Results are obtained by using the coefficients from the baseline M1 estimated on the estimation sample of 7,446 men for each year and projected both on the baseline data and on the policy simulation data.

accordance with the policy regime, the age dummies are adapted ex post facto. For the policy entailing a three-year shift in retirement age, this feature is modeled in the incentive variables and subsequently imposed on the age dummies (effectively shifting the hazard to the right by three years). In the case where the reform entails an actuarial adjustment by age, agedummy coefficients are adjusted by assuming that the underlying hazard should be smoother than the observed one. In order to impose this behavior, we make use of the information obtained in model M3 and adjust the age dummies according to a cubic function in age. The final effect of using model M3 is to preserve the important breaking points while making the rest of the simulated hazard smoother.

Results for men are presented in figures 6.15 (accrual and peak value) 

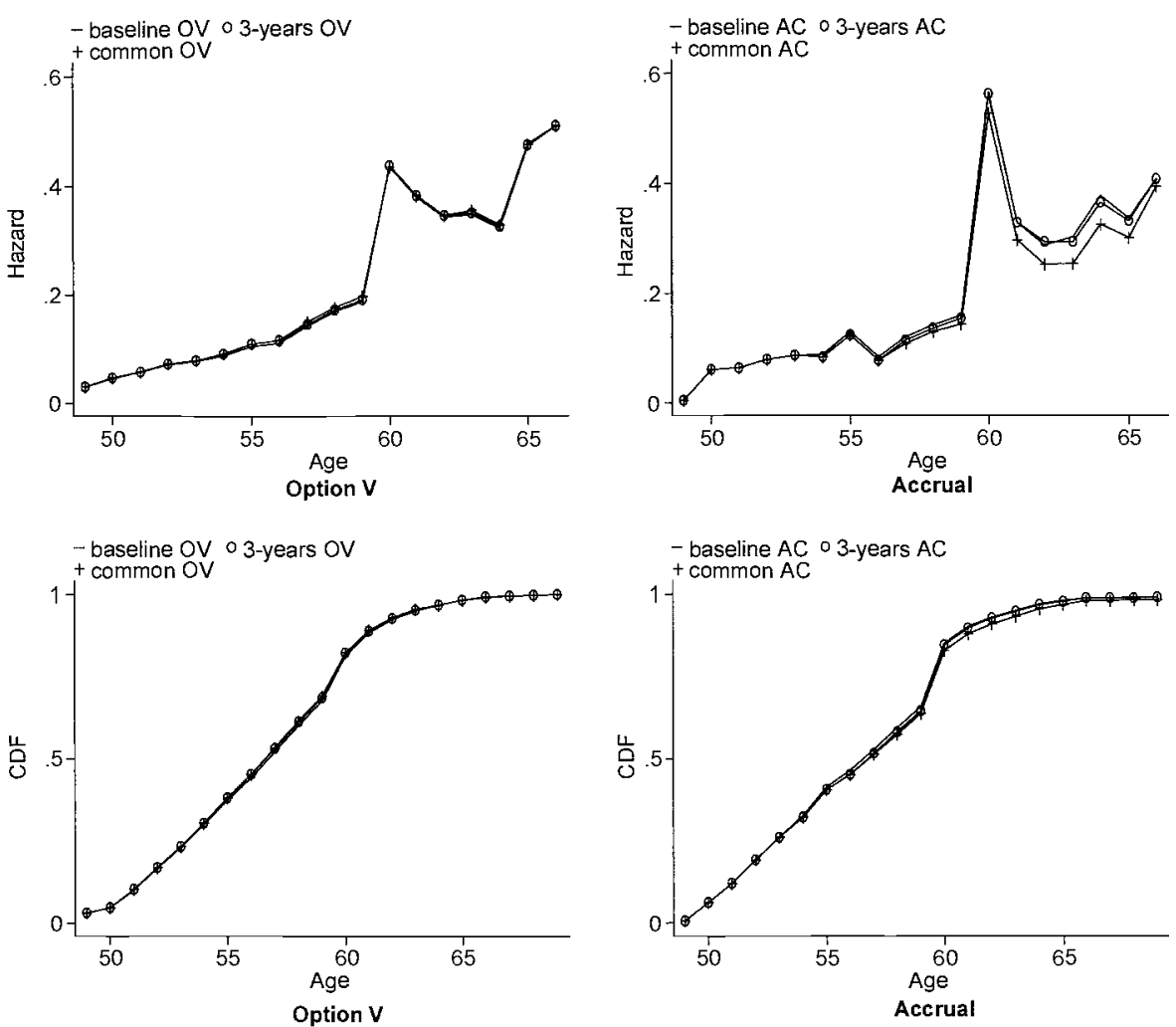

Fig. 6.12 Simulations M1-S1 for option value and M2-S2 for accrual, men

Note: The top panels show the hazards and the bottom panels the corresponding CDF. Results are obtained by using the coefficients from the baseline M1 estimated on the estimation sample of 7,446 men for each year and projected both on the baseline data and on the policy simulation data.

6.16 (option value) and for women in figure 6.17 (accrual only). The effects of policies are more marked than in the previous cases. In particular, both policies imply a tendency to delay retirement, as it is clearly documented by the CDF. The common reform has a stronger impact than the three-year shift. It is also interesting to note that under the common reform, the expost-facto adjustment of the age dummies smoothes out most spikes, leaving only one important spike at age sixty.

\section{Simulation S4 (Model M2)}

In this simulation, we consider the effects of the 1995 Dini reform described in section 6.2. This reform is in many respects similar to the common reform, as it computes benefits at each age according to an actuarial 

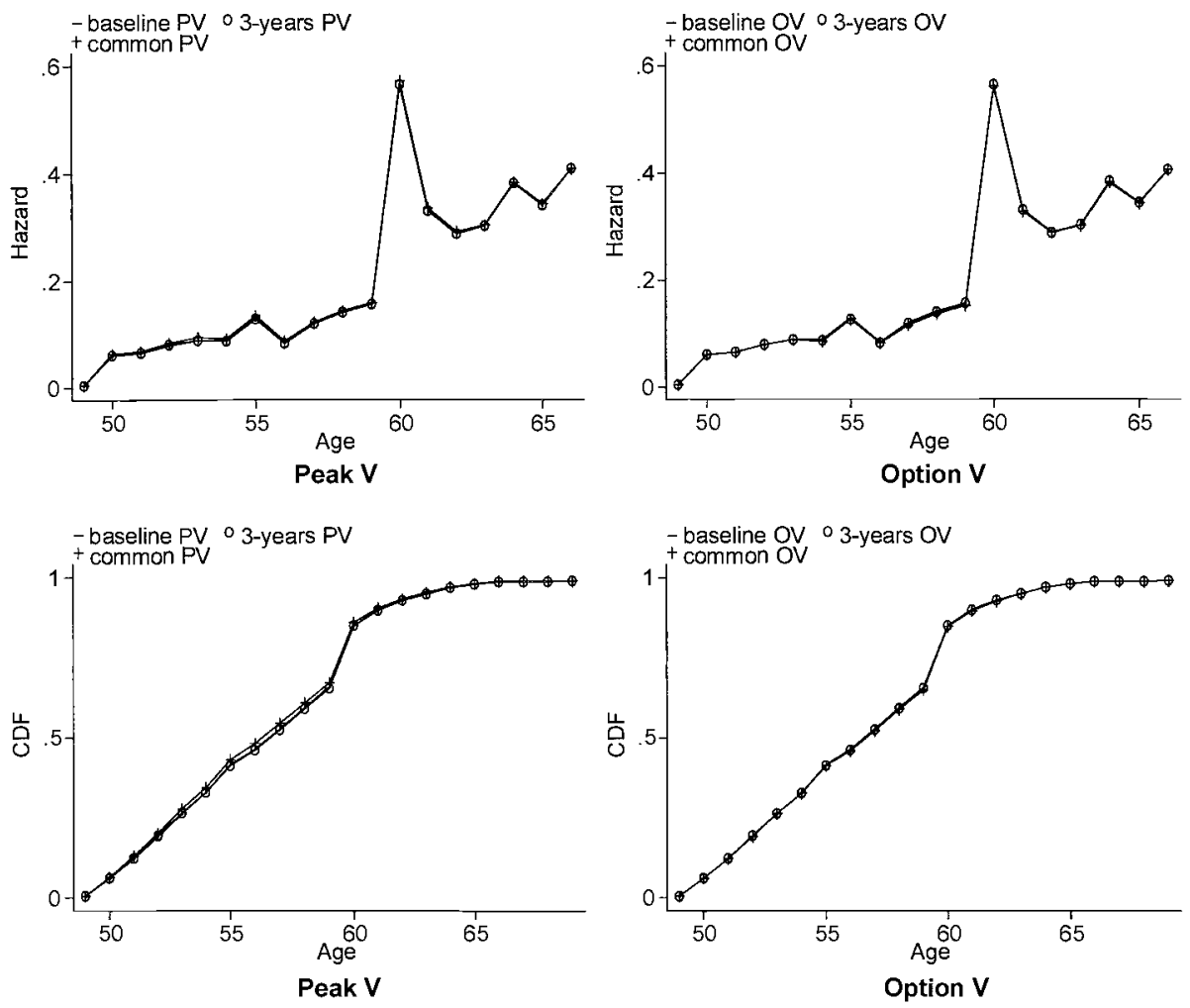

Fig. 6.13 Simulations M2-S2 for peak value and option value, men

Note: The top panels show the hazards and the bottom panels the corresponding CDF. Results are obtained by using the coefficients from the baseline M1 estimated on the estimation sample of 7,446 men for each year and projected both on the baseline data and on the policy simulation data.

adjustment factor and restricts retirement ages to a window. For this simulation, we contrast the estimated hazard with the baseline by looking at models M2 and M3 only. The results presented in figure 6.16 (right panels) suggest that the incentive measures do not have a strong impact in this case.

\section{Simulation S5 (Model M3)}

We look at the results obtained for the intermediate model M3 by contrasting the baseline and the policy changes. The assumption here is that the age polynomial should capture only preferences. Results for men are shown in figures 6.18 and 6.19. In particular, figure 6.18 and the left panel of figure 6.19 present the two hypothetical reforms, while the right panels 

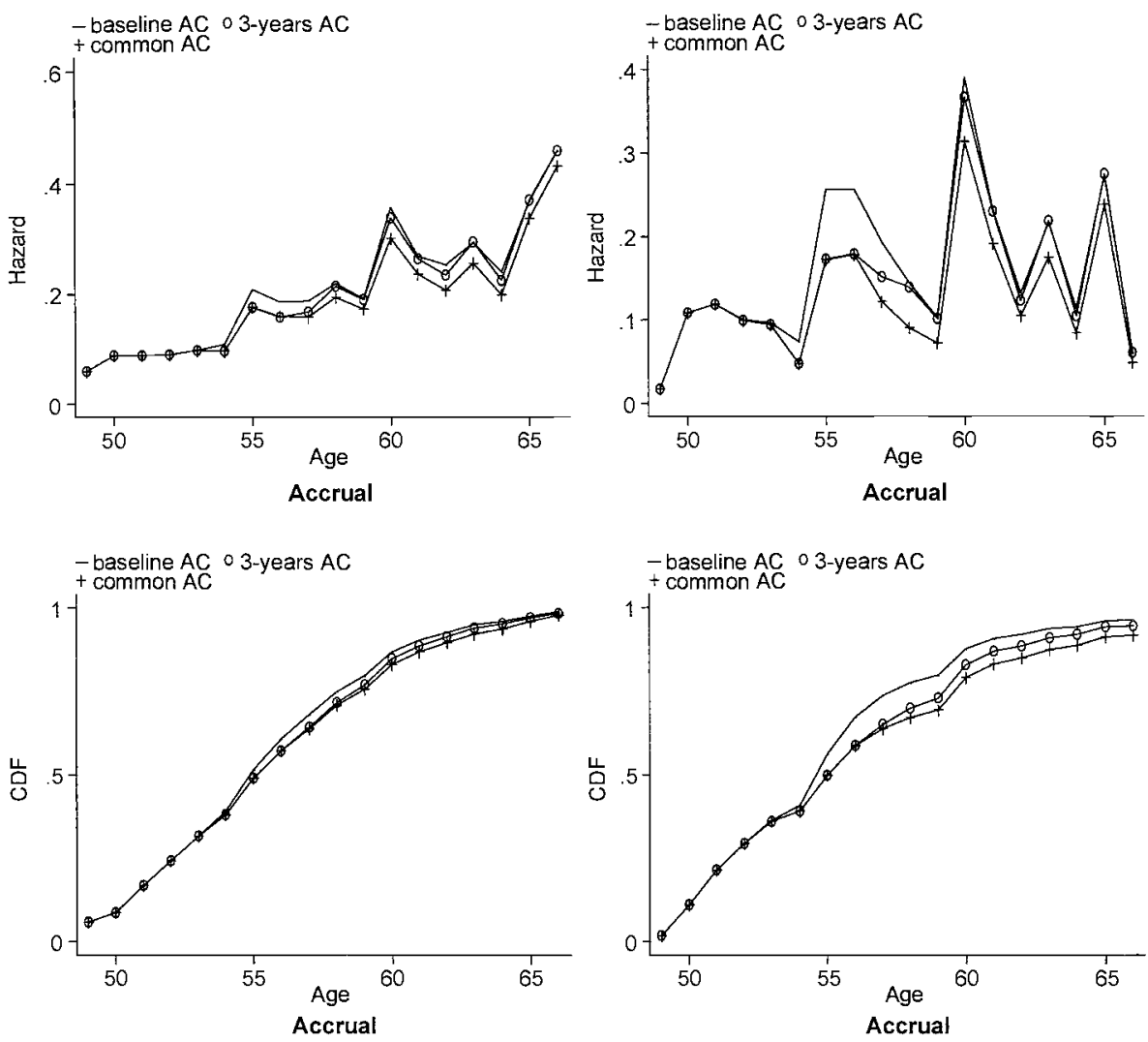

Fig. 6.14 Simulations M1-S1 and M2-S2 for accrual, women

Note: The top panels show the hazards and the bottom panels the corresponding CDF. Results are obtained by using the coefficients from the baseline M1 and then M2 estimated on the estimation sample of 1,770 women for each year and projected both on the baseline data and on the policy simulation data.

of figure 6.19 are for the actual 1995 reform. When incentives are measured by the accrual, there is a nonnegligible effect towards delayed retirement for both the common reform and the 1995 reform.

Finally, in figure 6.20 we carry out an experiment (only by making use of the accrual) that simulates the relevant policy changes on the basis of model M3. This is done by applying the incentive variables of the threeyear adjustment and the common reform on the basis of coefficients estimated under specification M3. At the same time, we shift forward the three important spikes (age fifty-five, sixty, and sixty-five) by three years, while leaving the cubic polynomial in age in its original form. Figure 6.20 presents the results, it suggests that we obtain significant changes in the hazard 

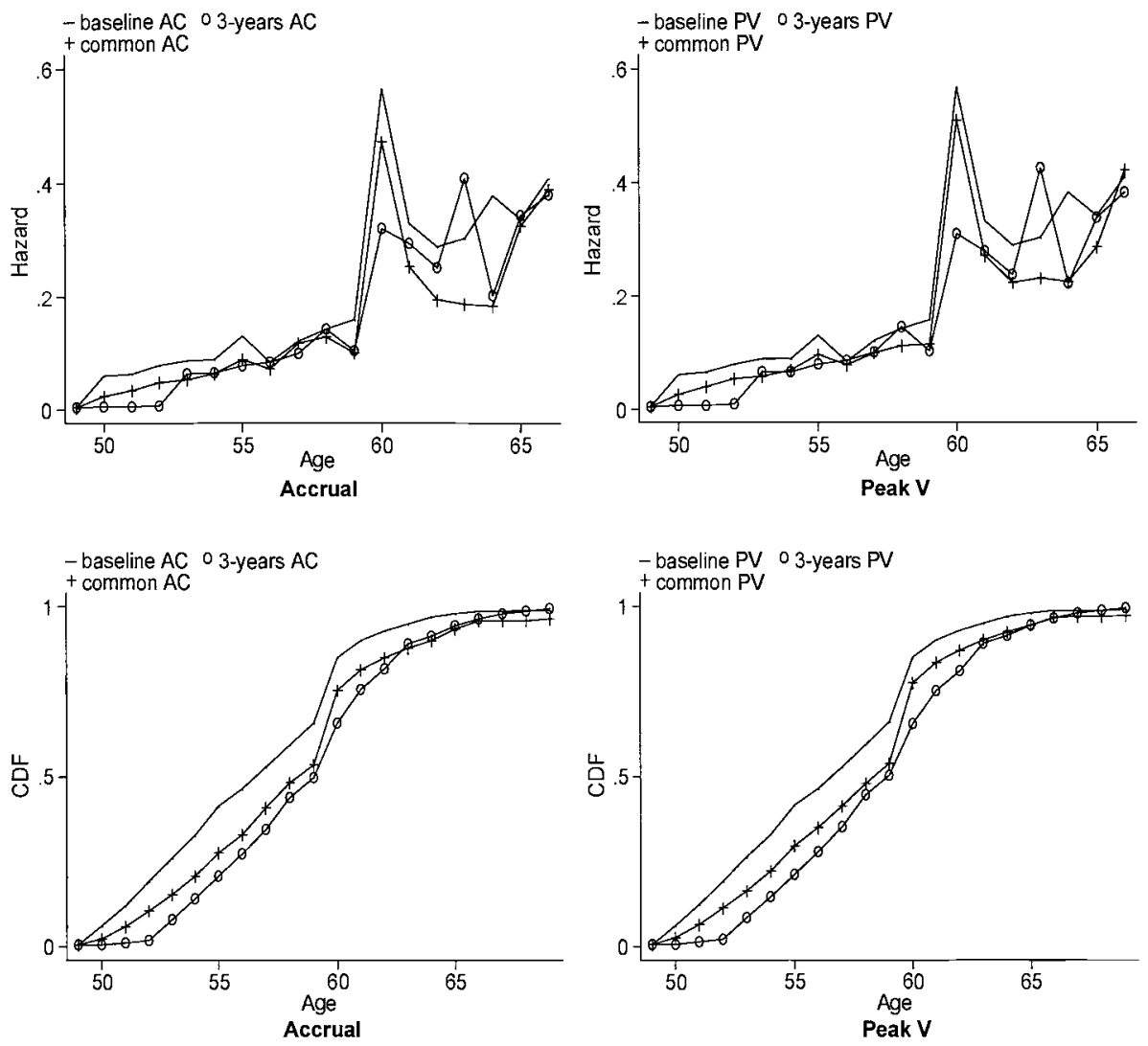

Fig. 6.15 Simulations M2-S3 for accrual and peak value, men

Note: The top panels show the hazards and the bottom panels the corresponding CDF. Results are obtained by using the coefficients from the baseline M1 estimated on the estimation sample of 7,446 men for each year and projected both on the baseline data and on the policy simulation data.

not only for the common reform, but also an impact on the CDF, leading to a nonnegligible increase in mean retirement age (see table 6.10).

\subsection{Conclusions}

This paper analyses retirement behavior of Italian workers by first estimating probit models and then making use of the econometric model to simulate exits from the labor force.

Results are mixed. The probit analysis provides, overall, a good fit for the estimated retirement hazards and the correct sign for the incentive variables (i.e., when the dynamic incentives increase workers tend to delay retirement). When comparing the models with actual behavior, one sees that, 

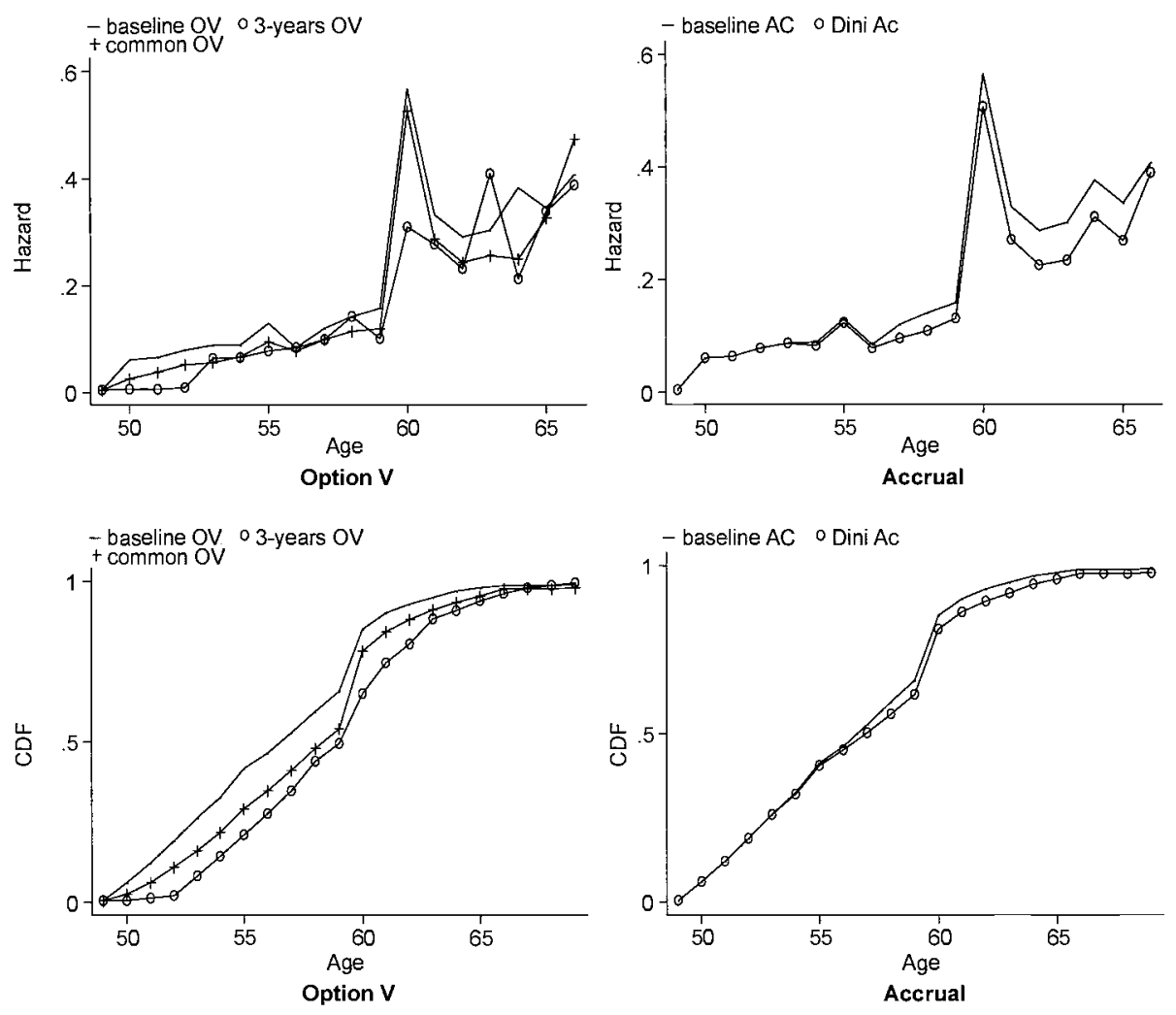

Fig. 6.16 Simulations M2-S3 for option value and simulation M2-S4 based on the legislation of the 1995 reform, men

Note: The top panels show the hazards and the bottom panels the corresponding CDF. Results are obtained by using the coefficients from the baseline M2 estimated on the estimation sample of 7,446 men for each year and projected both on the baseline data and on the policy simulation data. The right panels refer to the reform enacted in Italy in 1995 known as the Dini reform.

despite the adequate fit, all models tend to underestimate actual retirement as measured by mean retirement age (see table 6.10 for men). However, in this paper, the important comparison is between the baseline scenario and the simulated reforms. The reforms are implemented in two steps: first by allowing only for a change in the incentives (SSW as well as dynamic incentives) and then by looking at the full impact of the reforms through eligibility. However, while the effects of the reforms, as captured by the incentive variables, are clearly seen on the hazard, these are not of a significant magnitude. Of the incentive variables, the most effective is the accrual, and in some cases (e.g., model M2, simulation S3), we can see a substantial change in the hazard caused by the policy change. In particular, 

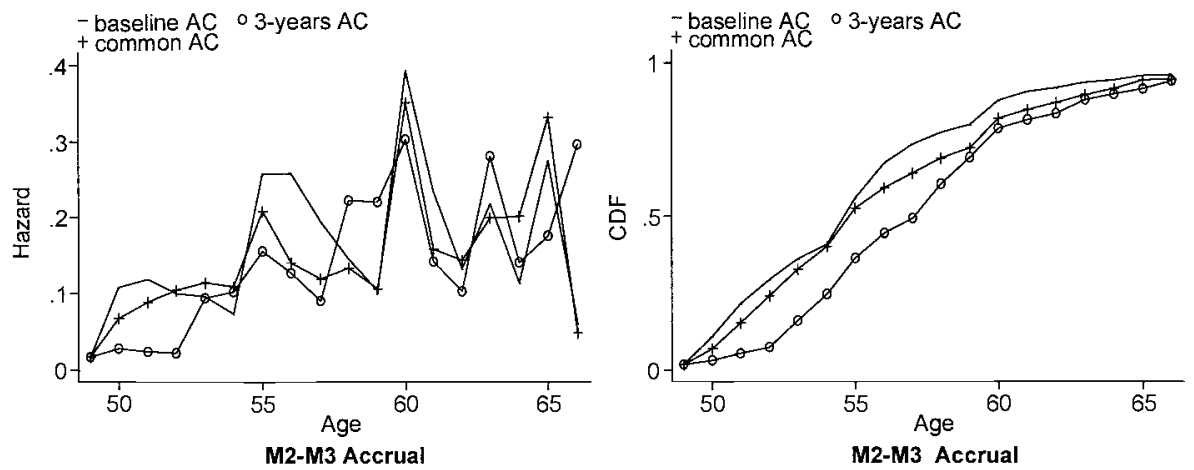

Fig. 6.17 Simulations M2-M3 for accrual, women

Note: The top panels show the hazards and the bottom panels the corresponding CDF. Results are obtained by using the coefficients from the baseline M1 and then M2 estimated on the estimation sample of 1,770 women for each year and projected both on the baseline data and on the policy simulation data.
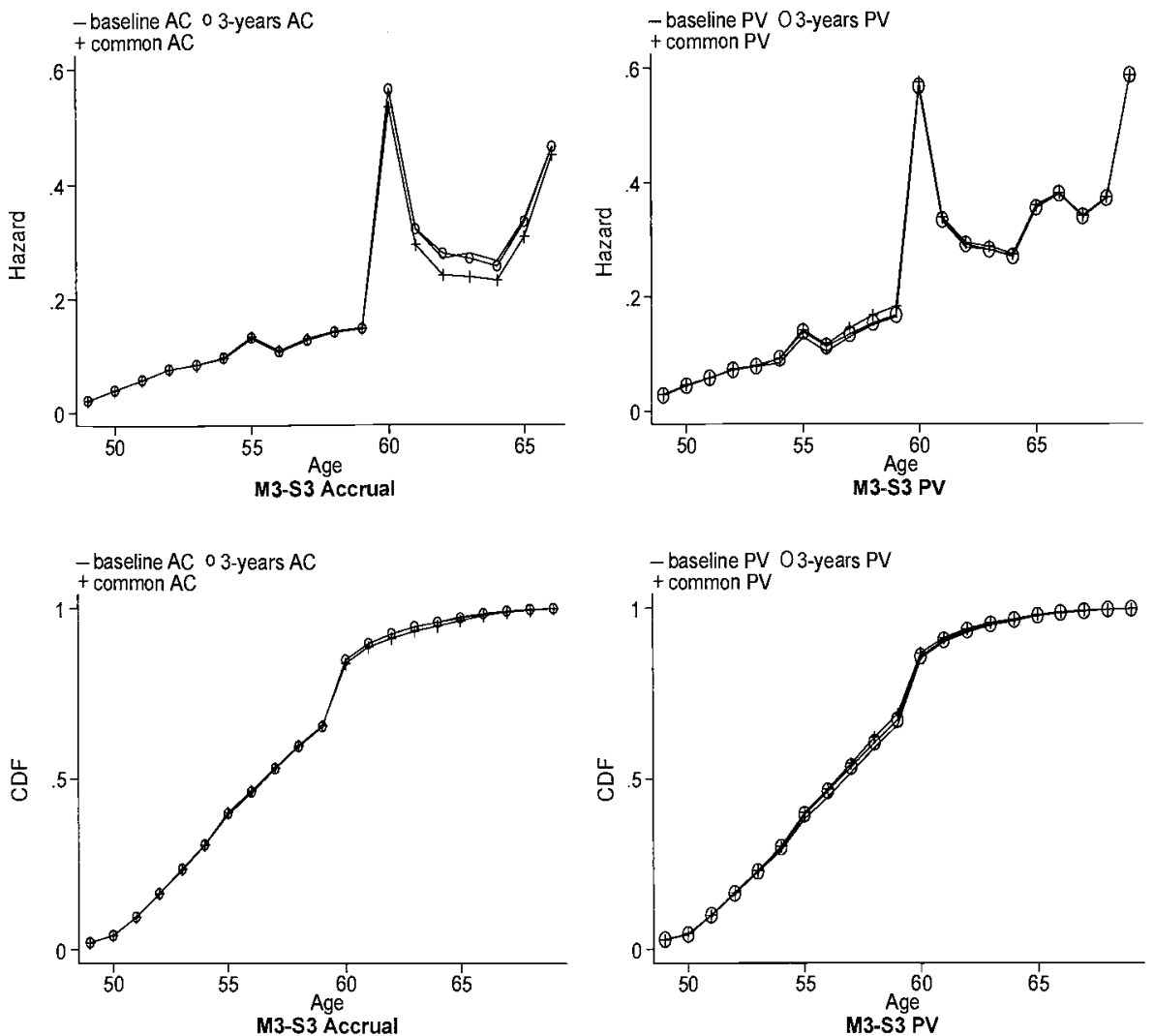

Fig. 6.18 Simulation M3 based on a flexible specification of the age effects, men

Notes: Results for the simulated hazards are obtained by using the coefficients from the baseline M3 estimated on the estimation sample of 7,664 men for each year. The left panel makes use of the accrual value and the right panels of the peak value for the baseline and for the policy changes. 

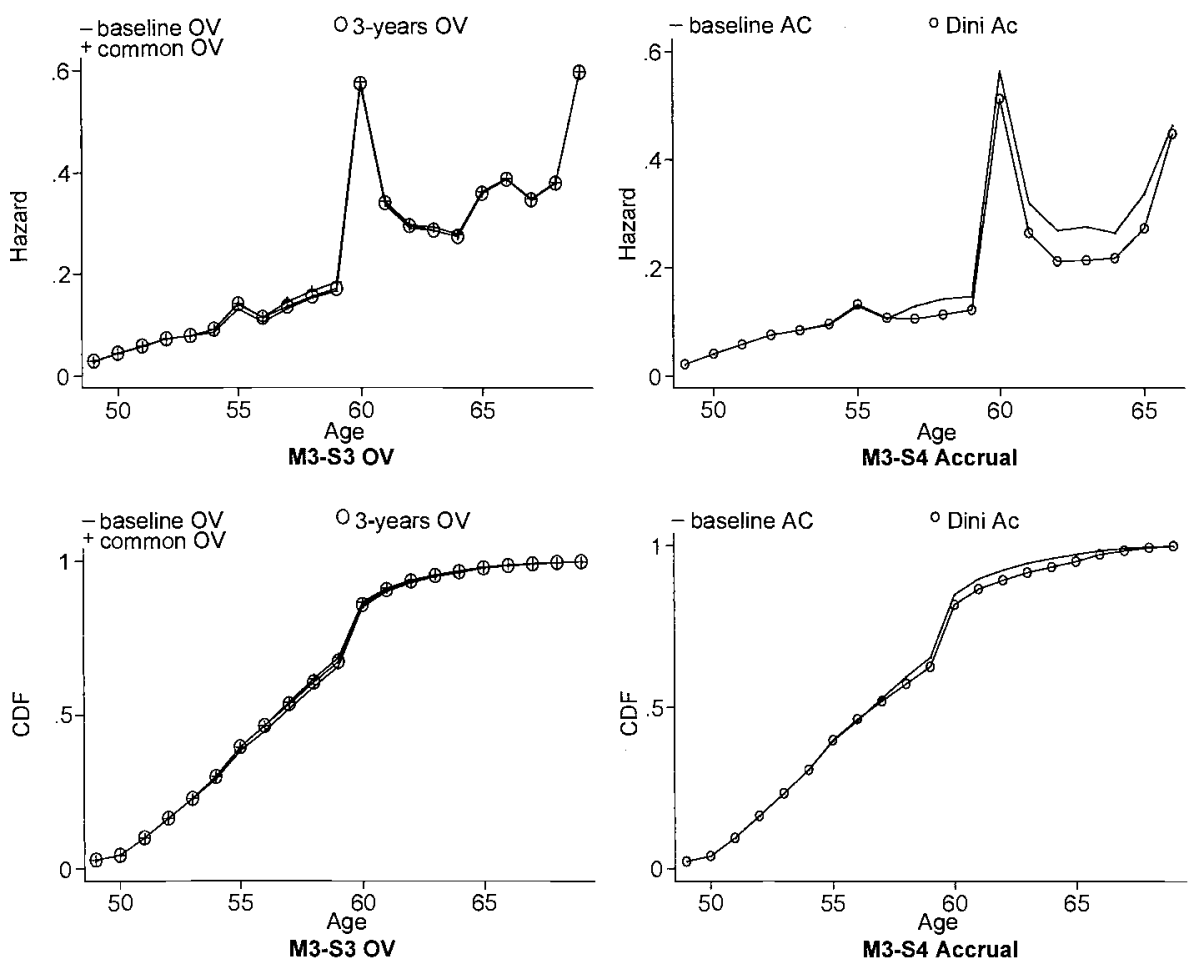

Fig. 6.19 Simulation M3 based on a flexible specification of the age effects, men

Note: Results for the simulated hazards are obtained by using the coefficients from the baseline M3 estimated on the sample of 7,664 men for each year. The left panel makes use of the option value for the standard reforms and the right panels make use of the accrual value for the 1995 reform.

both the hypothetical common reform (based on an actuarially-fair scheme) and the actual 1995 reform show a clear move toward an ageneutral system as opposed to the baseline scenario. However, this is not always sufficient to produce significant changes in mean retirement age and in the unconditional retirement probabilities as described by the CDF. 

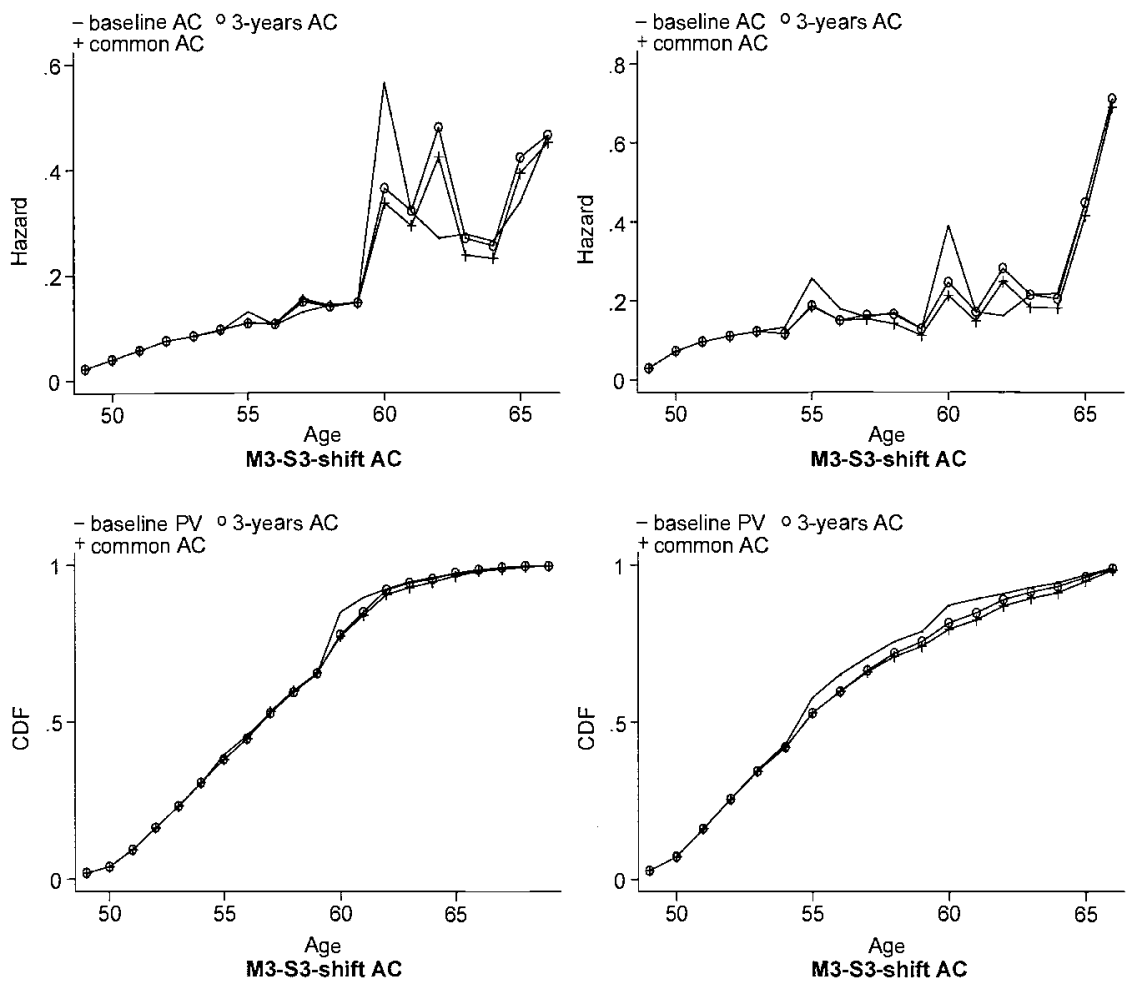

Fig. 6.20 Simulation M3 based on flexible specification of the age effects

Note: The left panels are for men and the right panels for women. Results for the simulated hazards are obtained by using the coefficients from the baseline M3. In this model, we shift the three important dummies by three years in order to impose an age effect due to the policy change.

Table 6.10

Estimated Mean Retirement Age of Men (estimation sample: $N=7,664$ )

\begin{tabular}{lcccc}
\hline & Baseline & Three-Year Reform & Common Reform & 1995 Reform \\
\hline M1-S1-ACC & 55.23 & 55.23 & 55.24 & 55.43 \\
M1-S1-Peak V & 55.26 & 55.19 & 55.25 & 55.19 \\
M1-S1-OV & 55.28 & 55.18 & 55.16 & 54.95 \\
M2-S2-ACC & 55.97 & 56.01 & 55.81 & 55.71 \\
M2-S2-Peak V & 55.92 & 55.93 & 55.80 & 55.92 \\
M2-S2-OV & 55.93 & 55.97 & 55.94 & 55.81 \\
M2-S3-ACC & 58.35 & 58.45 & 58.41 & 58.58 \\
M2-S3-Peak V & 58.40 & 58.42 & 58.32 & 58.43 \\
M2-S3-OV & 58.43 & 58.45 & 58.66 & 58.38 \\
M3-ACC & 55.71 & 55.70 & 55.74 & 55.90 \\
M3-S5-ACC & & 55.84 & 55.88 & \\
\hline
\end{tabular}

Notes: Sample mean retirement age $=56.63 . \mathrm{ACC}=$ accrual value $; \mathrm{OV}=$ option value. Unconditional mean retirement age is based on the CDF corresponding to each case (for example, M2-S3-OV gives the mean retirement age corresponding to the simulated retirement probabilities based on model M2, policy S3, when the incentive variable is the option value). For model M3, case S5, ACC, mean retirement ages for the baseline and the 1995 reform are not shown as the eligibility rules of these cases are not coherent with the policy change under investigation. Blank cells indicate that no calculation was done in that case. 


\section{Appendix}

Table 6A.1

Summaries of the Distribution of Social Security Wealth and Incentive Measures for Men, by Age

\begin{tabular}{|c|c|c|c|c|c|c|c|c|}
\hline \multirow[b]{2}{*}{ Age } & \multirow{2}{*}{$\begin{array}{c}\text { Median } \\
\text { SSW }\end{array}$} & \multicolumn{4}{|c|}{ Accrual } & \multirow{2}{*}{$\begin{array}{c}\text { Median } \\
\text { Tax/Subsidy }\end{array}$} & \multirow[b]{2}{*}{ Observations } & \multirow{2}{*}{$\begin{array}{c}\text { From } \\
\text { Volume }\end{array}$} \\
\hline & & Median & $10 \%$ & $90 \%$ & $\mathrm{SD}$ & & & \\
\hline \multicolumn{9}{|c|}{ Baseline (Transition) Case } \\
\hline 53 & 0 & 0 & 0 & 0 & 1.20 & 0 & 712 & \\
\hline 54 & 112.48 & 0 & -4.60 & .051 & 6.40 & 0 & 641 & \\
\hline 55 & 129.96 & -1.00 & -7.68 & 0 & 6.50 & .102 & 600 & .282 \\
\hline 56 & 135.52 & -1.25 & -7.69 & .082 & 7.04 & .124 & 516 & .301 \\
\hline 57 & 142.30 & -2.61 & -16.78 & .867 & 8.48 & .287 & 466 & .326 \\
\hline 58 & 137.97 & -2.66 & -16.19 & .666 & 8.48 & .298 & 405 & .356 \\
\hline 59 & 134.32 & -3.69 & -13.40 & 0 & 7.10 & .403 & 333 & .378 \\
\hline 60 & 129.30 & -9.76 & -21.44 & -1.86 & 11.075 & 1.634 & 279 & .623 \\
\hline 61 & 128.73 & -4.42 & -23.55 & -.111 & 13.54 & .528 & 110 & .632 \\
\hline 62 & 126.19 & -4.87 & -23.23 & 0.983 & 11.82 & .591 & 69 & .633 \\
\hline 63 & 124.46 & -4.96 & -23.037 & -1.00 & 10.80 & .628 & 46 & .638 \\
\hline 64 & 120.36 & -4.49 & -20.233 & 1.63 & 17.15 & .487 & 32 & .648 \\
\hline 65 & 101.24 & -4.91 & -20.94 & -1.99 & 13.32 & 0.923 & 39 & .651 \\
\hline \multicolumn{9}{|c|}{ Post-1995 (DINI) Case } \\
\hline 53 & 0 & 0 & 0 & 0 & 0 & 0 & 712 & \\
\hline 54 & 0 & 0 & 0 & 0 & 0 & 0 & 641 & \\
\hline 55 & 0 & 0 & 0 & 0 & 0 & 0 & 600 & \\
\hline 56 & 0 & 0 & 0 & 0 & 0 & 0 & 516 & \\
\hline 57 & 116.62 & 0.33 & -1.065 & 4.43 & 3.41 & -.034 & 466 & \\
\hline 58 & 115.51 & 1.42 & -1.195 & 7.23 & 5.19 & -.111 & 405 & \\
\hline 59 & 114.48 & -.59 & -2.00 & 2.90 & 4.06 & .063 & 333 & \\
\hline 60 & 112.90 & -1.23 & -2.59 & 2.24 & 4.62 & .154 & 279 & \\
\hline 61 & 117.25 & -.775 & -2.69 & 6.64 & 6.60 & .123 & 110 & \\
\hline 62 & 114.98 & .084 & -1.08 & 13.94 & 7.13 & .009 & 69 & \\
\hline 63 & 111.96 & .065 & -.93 & 24 & 8.29 & -.006 & 46 & \\
\hline 64 & 117.41 & .132 & -.94 & 15.49 & 8.19 & -.015 & 32 & \\
\hline 65 & 95.36 & -2.18 & -3.14 & 1.09 & 1.56 & .256 & 39 & \\
\hline \multicolumn{9}{|c|}{ Simulation (3-year Increment) } \\
\hline 53 & 0 & 0 & 0 & 0 & 0 & 0 & 712 & \\
\hline 54 & 0 & 0 & 0 & 0 & 0 & 0 & 641 & \\
\hline 55 & 0 & 0 & 0 & 0 & 0 & 0 & 600 & \\
\hline 56 & 0 & 0 & 0 & 0 & 0 & 0 & 516 & \\
\hline 57 & 129.25 & -.504 & -5.69 & 0 & 5.53 & .057 & 466 & \\
\hline 58 & 128.65 & -1.37 & -6.94 & 0 & 5.71 & .136 & 405 & \\
\hline 59 & 126.59 & -2.72 & -8.25 & 0 & 5.57 & .338 & 333 & \\
\hline 60 & 126.83 & -8.41 & -19.72 & 0 & 8.71 & 1.21 & 279 & \\
\hline 61 & 127.18 & -4.27 & -21.99 & 0 & 10.45 & .496 & 110 & \\
\hline 62 & 120.34 & -4.6 & -23.23 & 0 & 8.36 & .591 & 69 & \\
\hline 63 & 124.46 & -4.18 & -21.29 & -1.00 & 9.67 & .496 & 46 & \\
\hline 64 & 120.85 & -4.49 & -20.23 & 1.64 & 14.59 & .500 & 32 & \\
\hline $\begin{array}{l}65 \\
\text { (con }\end{array}$ & $\begin{array}{l}102.4 \\
\text { led) }\end{array}$ & -4.91 & -20.94 & -1.99 & 13.32 & .659 & 39 & \\
\hline
\end{tabular}




\begin{tabular}{|c|c|c|c|c|c|c|c|c|c|}
\hline \multirow[b]{2}{*}{ Age } & \multirow{2}{*}{$\begin{array}{l}\text { Median } \\
\text { SSW }\end{array}$} & \multicolumn{4}{|c|}{ Accrual } & \multirow{2}{*}{\multicolumn{2}{|c|}{$\begin{array}{c}\text { Median } \\
\text { Tax/Subsidy }\end{array}$}} & \multirow[b]{2}{*}{ Observations } & \multirow{2}{*}{$\begin{array}{l}\text { From } \\
\text { Volume }\end{array}$} \\
\hline & & Median & $10 \%$ & $90 \%$ & $\mathrm{SD}$ & & & & \\
\hline \multicolumn{10}{|c|}{ Common Reform (Act. Adjustment) } \\
\hline 53 & 0 & 0 & 0 & 0 & 0 & 0 & & 712 & \\
\hline 54 & 0 & 0 & 0 & 0 & 0 & 0 & & 641 & \\
\hline 55 & 0 & 0 & 0 & 0 & 0 & 0 & & 600 & \\
\hline 56 & 0 & 0 & 0 & 0 & 0 & 0 & & 516 & \\
\hline 57 & 0 & 0 & 0 & 0 & 0 & 0 & & 466 & \\
\hline 58 & 0 & 0 & 0 & 0 & 0 & 0 & & 405 & \\
\hline 59 & 0 & 0 & 0 & 0 & 0 & 0 & & 333 & \\
\hline 60 & 83.88 & -2.18 & -11.30 & 5.69 & 6.94 & .65 & & 279 & \\
\hline 61 & 94.64 & -.356 & -18.93 & 7.44 & 11.51 & .03 & & 110 & \\
\hline 62 & 100.14 & -.623 & -10.53 & 6.18 & 13.27 & .06 & & 69 & \\
\hline 63 & 105.87 & -.602 & -8.97 & 24.11 & 12.52 & .06 & & 46 & \\
\hline 64 & 105.12 & -1.259 & -11.06 & 3.79 & 13.80 & .11 & & 32 & \\
\hline \multirow[t]{3}{*}{65} & 89.84 & -2.02 & -13.71 & 6.80 & 10.41 & .35 & & 39 & \\
\hline & \multicolumn{5}{|c|}{ Peak Value } & \multicolumn{4}{|c|}{ Option Value } \\
\hline & Median & $10 \%$ & $90 \%$ & & SD & Median & $10 \%$ & $90 \%$ & $\mathrm{SD}$ \\
\hline \multicolumn{10}{|c|}{ Baseline (Transition) Case } \\
\hline 53 & 147.90 & 69.35 & 187.01 & & 54.86 & 301.17 & 114.81 & 531.27 & 219.23 \\
\hline 54 & 3.27 & -4.61 & 174.19 & & 33.58 & 143.20 & 48.06 & 477.51 & 234.33 \\
\hline 55 & -.659 & -7.15 & 176.58 & & 35.00 & 123.77 & 11.68 & 474.82 & 231.79 \\
\hline 56 & -1.17 & -7.69 & 178.90 & & 31.57 & 112.70 & 20.86 & 450.28 & 206.05 \\
\hline 57 & -2.58 & -15.44 & 64.90 & & 47.49 & 99.78 & 12.75 & 248.62 & 140.10 \\
\hline 58 & -2.66 & -16.11 & 41.13 & & 44.33 & 89.48 & -1.29 & 246.70 & 145.95 \\
\hline 59 & -3.56 & -13.40 & 14.46 & & 45.34 & 79.33 & -2.53 & 221.00 & 154.66 \\
\hline 60 & -9.76 & -21.44 & -1.76 & & 15.61 & -0.825 & -22.6 & 143.92 & 125.00 \\
\hline 61 & -4.42 & -23.55 & 2.49 & & 18.97 & 53.27 & -25.63 & 254.06 & 164.45 \\
\hline 62 & -4.68 & -23.23 & 1.83 & & 14.49 & 51.99 & -20.24 & 366.24 & 165.17 \\
\hline 63 & -4.96 & -23.04 & -1.00 & & 14.00 & 45.16 & -24.30 & 428.20 & 171.61 \\
\hline 64 & -4.49 & -20.23 & -2.85 & & 18.72 & 45.20 & -6.4 & 136.25 & 125.76 \\
\hline 65 & -5.24 & -23.47 & -1.99 & & 14.54 & 10.01 & -25.09 & 81.99 & 54.87 \\
\hline \multicolumn{10}{|c|}{1995 Reform Case } \\
\hline 53 & 123.39 & 92.12 & 182.56 & & 63.2 & 334.11 & 171.18 & 598.8 & 248.99 \\
\hline 54 & 121.76 & 88.57 & 177.31 & & 61.52 & 325.63 & 156.24 & 567.08 & 235.53 \\
\hline 55 & 120.33 & 88.40 & 173.22 & & 65.30 & 309.88 & 153.79 & 549.60 & 231.53 \\
\hline 56 & 119.27 & 85.38 & 169.36 & & 66.59 & 300.34 & 159.76 & 538.11 & 213.15 \\
\hline 57 & 5.72 & -.94 & 58.08 & & 34.45 & 157.37 & 47.52 & 322.79 & 154.98 \\
\hline 58 & 4.53 & -1.17 & 57.38 & & 5.715 & 142.32 & 38.39 & 298.18 & 164.90 \\
\hline 59 & -.485 & -1.96 & 60.29 & & 31.86 & 128.35 & 28.38 & 255.88 & 163.95 \\
\hline 60 & -1.14 & -2.56 & 52.94 & & 31.08 & 51.42 & 3.70 & 230.24 & 160.40 \\
\hline 61 & -.246 & -2.70 & 60.33 & & 34.84 & 95.46 & -1.91 & 373.90 & 205.02 \\
\hline 62 & .425 & -1.08 & 56.27 & & 29.00 & 94.09 & 3.04 & 551.25 & 206.55 \\
\hline 63 & .161 & -.938 & 56.48 & & 24.06 & 81.32 & 6.90 & 601.55 & 208.60 \\
\hline 64 & .132 & -.94 & 35.13 & & 4.40 & 68.84 & 16.25 & 397.06 & 161.15 \\
\hline 65 & -2.18 & -3.14 & 2.52 & & 2.17 & 33.55 & -3.00 & 110.98 & 78.62 \\
\hline
\end{tabular}


(continued)

\begin{tabular}{|c|c|c|c|c|c|c|c|c|}
\hline & \multicolumn{4}{|c|}{ Peak Value } & \multicolumn{4}{|c|}{ Option Value } \\
\hline & Median & $10 \%$ & $90 \%$ & $\mathrm{SD}$ & Median & $10 \%$ & $90 \%$ & $\mathrm{SD}$ \\
\hline \multicolumn{9}{|c|}{ Simulation 1 Case } \\
\hline 53 & 143.40 & 69.39 & 179.69 & 51.07 & 316.72 & 119.70 & 545.38 & 219.99 \\
\hline 54 & 143.95 & 69.42 & 179.13 & 50.78 & 311.10 & 106.85 & 516.38 & 208.64 \\
\hline 55 & 140.52 & 56.24 & 176.99 & 62.86 & 290.96 & 94.64 & 496.41 & 211.96 \\
\hline 56 & 139.49 & 13.07 & 176.49 & 61.70 & 279.56 & 96.34 & 491.54 & 187.54 \\
\hline 57 & -.285 & -5.69 & 167.40 & 79.23 & 123.54 & 39.37 & 450.03 & 191.51 \\
\hline 58 & -1.24 & -6.91 & 169.64 & 83.48 & 107.79 & 16.20 & 425.61 & 204.80 \\
\hline 59 & -2.72 & -8.25 & 168.42 & 85.68 & 92.74 & .328 & 396.20 & 210.26 \\
\hline 60 & -8.42 & -19.72 & 56.06 & 58.54 & 3.36 & -21.58 & 205.77 & 174.40 \\
\hline 61 & -4.27 & -21.99 & 35.56 & 82.81 & 59.44 & -25.22 & 346.32 & 243.86 \\
\hline 62 & -4.60 & -23.23 & 192.40 & 100.64 & 64.56 & -20.51 & 553.95 & 270.40 \\
\hline 63 & -4.18 & -21.29 & -1.00 & 12.94 & 52.15 & -10.81 & 462.73 & 176.74 \\
\hline 64 & -4.06 & -20.23 & 2.06 & 16.36 & 53.09 & -6.40 & 157.65 & 139.04 \\
\hline 65 & -4.91 & -20.94 & -1.99 & 14.19 & 19.99 & -20.61 & 88.68 & 56.24 \\
\hline \multicolumn{9}{|c|}{ Simulation 2 Case } \\
\hline 53 & 102.58 & 62.73 & 135.40 & 42.61 & 315.54 & 119.56 & 544.01 & 228.55 \\
\hline 54 & 103.13 & 62.69 & 133.10 & 42.12 & 309.91 & 102.55 & 514.72 & 216.92 \\
\hline 55 & 102.07 & 62.69 & 133.14 & 43.55 & 295.40 & 105.73 & 494.77 & 212.44 \\
\hline 56 & 102.87 & 62.73 & 135.32 & 37.43 & 288.26 & 111.34 & 490.25 & 183.38 \\
\hline 57 & 101.34 & 62.69 & 133.16 & 35.60 & 272.98 & 102.65 & 455.71 & 167.42 \\
\hline 58 & 100.84 & 62.69 & 134.74 & 40.62 & 260.22 & 98.26 & 440.76 & 181.99 \\
\hline 59 & 101.02 & 62.73 & 131.10 & 45.08 & 248.52 & 89.50 & 398.04 & 189.26 \\
\hline 60 & -2.18 & -11.30 & 15.22 & 25.95 & 17.88 & -9.96 & 202.95 & 161.45 \\
\hline 61 & -.116 & -18.93 & 19.35 & 39.72 & 103.99 & -21.86 & 332.89 & 216.70 \\
\hline 62 & -.624 & -10.53 & 61.64 & 42.41 & 96.24 & -4.60 & 566.63 & 224.92 \\
\hline 63 & -.371 & -8.95 & 85.52 & 44.06 & 82.96 & -1.88 & 653.44 & 233.20 \\
\hline 64 & -.91 & -11.06 & 31.29 & 29.24 & 74.46 & -1.30 & 283.30 & 171.98 \\
\hline 65 & -2.02 & -13.71 & 6.80 & 12.80 & 25.13 & -15.89 & 105.05 & 75.21 \\
\hline
\end{tabular}

Note: $\mathrm{SD}=$ standard deviation .

\section{References}

Brugiavini, A. 1999. Social security and retirement in Italy. In Social security and retirement around the world, ed. J. Gruber and D. Wise, 181-237. Chicago: University of Chicago Press.

Colombino, U. 2000. Un modello per la valutazione degli effetti degli incentivi individuali sulle decisioni di pensionamento (A model for evaluating the effects of individual incentives on retirement decisions). University of Turin, Department of Economics. Mimeograph.

Franco, D. 2000. Italy: A never-ending pension reform. Paper presented at NBERKiel Institute Conference, Coping with the Pension Crisis-Where Does Europe Stand? 20-21 March, Berlin, Germany.

Gruber, J., and D. Wise. 1999. Social security and retirement around the world. Chicago: University of Chicago Press.

Instituto Nazionale della Previdenza Sociale (INPS). 1995. Il modello INPS. Una 
proiezione al 2030 del Fondo pensioni lavoratori dipendenti e delle Gestion i pensionistiche dei lavoratori autonomi (The INPS model. A projection to year 2030 of the pension funds of private sector employees and self-employed workers). Rome: INPS. Mimeograph.

Instituto Nazionale di Statistica (ISTAT). Various years. I trattamenti pensionistici. Rome: ISTAT.

Miniaci, R. 1998. Microeconometric analysis of the retirement decision in Italy. Organization for Economic Cooperation and Development (OECD) Economics Department Working Paper no. 205. Paris: OECD.

Rossi, N., A. Sorgato, and G. Toniolo. 1993. I conti economici italiani: Una ricostruzione statistica, 1890-1990 (The Italian national accounts: A statistical reconstruction, 1890-1990). Rivista di Storia Economica 10 (1): 1-47.

Spataro, L. 2000. Le scelte di pensionamento in Italia: Un'applicazione (ed estensione) del modello "option value" (Retirement choices in Italy: An application [and extension] of the option value model). Studi Economici 72:1-30.

Stock, J. H., and D. A. Wise. 1990. Pensions, the option value of work, and retirement. Econometrica 58 (5): 1151-80.

Zweimüller, J., R. Winter-Ebmer, and J. Falkinger. 1996. Retirement of spouses and social security reform. European Economic Review 40 (2): 449-72. 